LBNL-53729-Revised

\title{
After-hours Power Status of Office Equipment and Energy Use of Miscellaneous Plug-Load Equipment
}

\author{
Judy A. Roberson, Carrie A. Webber, Marla C. McWhinney, \\ Richard E. Brown, Margaret J. Pinckard, and John F. Busch \\ Energy Analysis Department \\ Environmental Energy Technologies Division \\ Ernest Orlando Lawrence Berkeley National Laboratory \\ University of California \\ Berkeley CA 94720, USA
}

May 2004

To download this paper and related data go to:

http://enduse.lbl.gov/Projects/OffEqpt.html

The work described in this paper was supported by the Office of Atmospheric Programs, Climate Protection Partnerships Division of the U.S. Environmental Protection Agency and prepared for the U.S. Department of Energy under Contract No. DE-AC03-76SF00098. 


\section{Table of Contents}

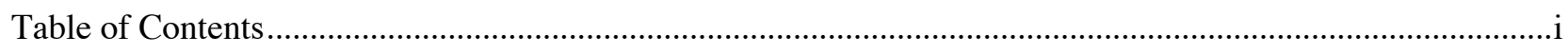

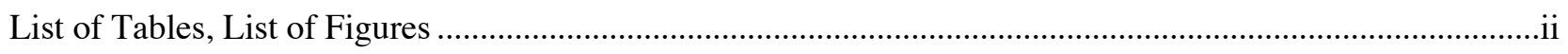

Abbreviations, Acronyms, and Glossary of Terms ..................................................................................

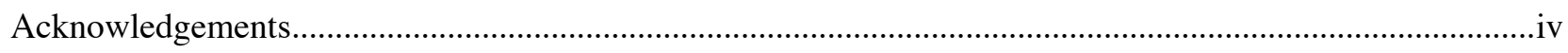

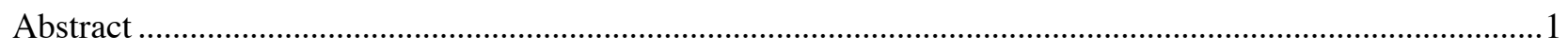

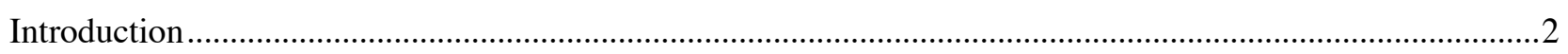

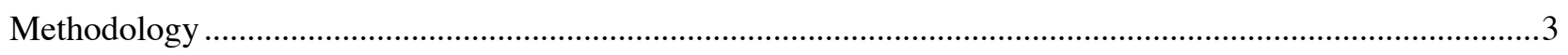

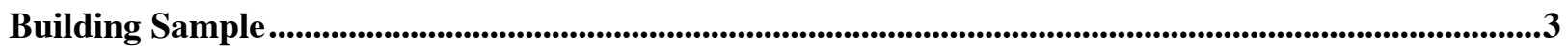

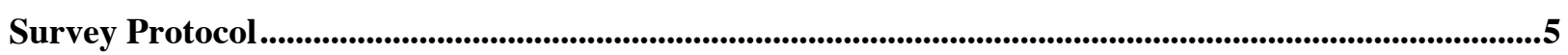

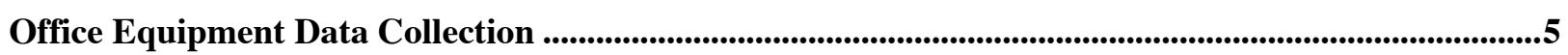

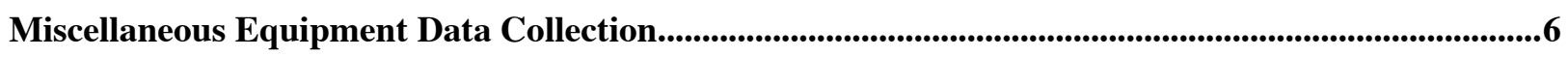

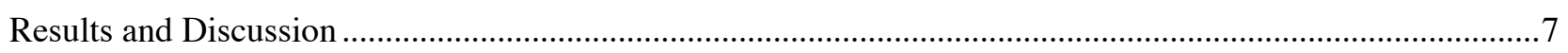

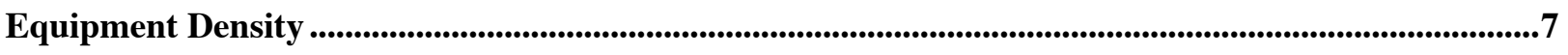

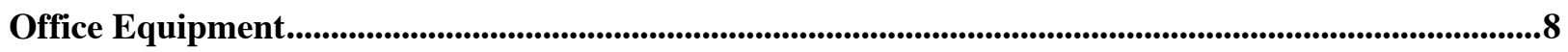

Computers

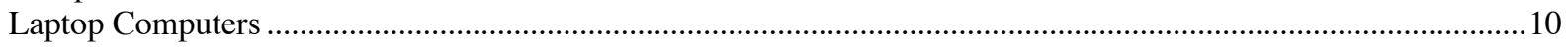

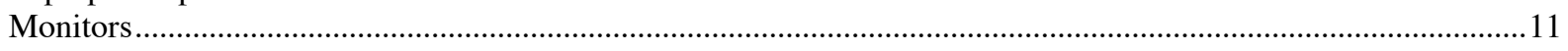

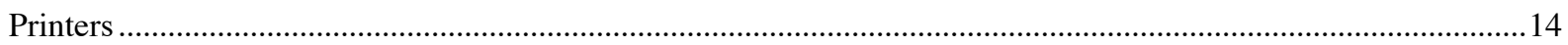

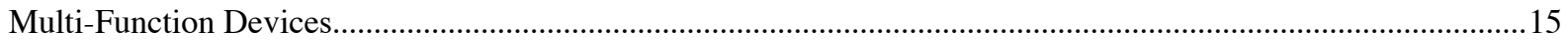

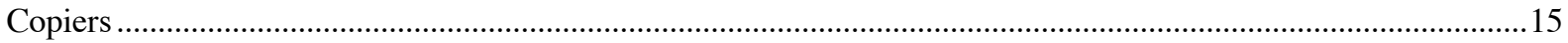

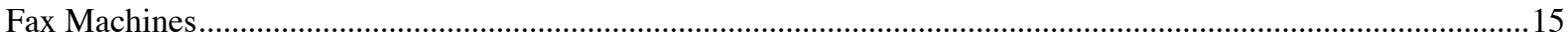

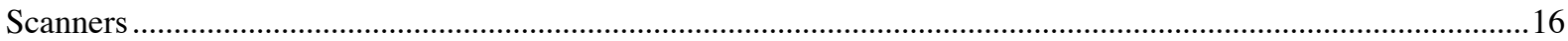

Office Equipment: Comparison of 2000 and 2003 Turn-off and PM Rates ................................................16

Miscellaneous Equipment .............................................................................................................................................................17

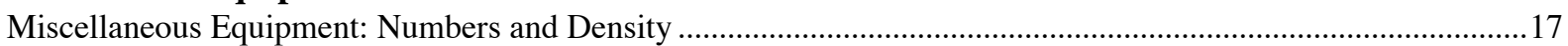

Miscellaneous Equipment: Relative Energy Consumption .....................................................................................19

External Power Supplies............................................................................................................................................24

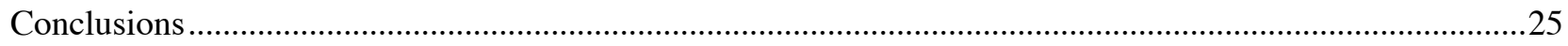

Office Equipment.........................................................................................................................................................25

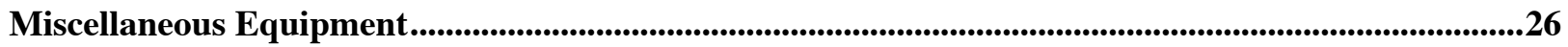

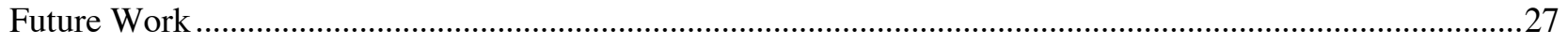

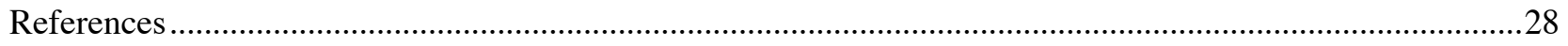

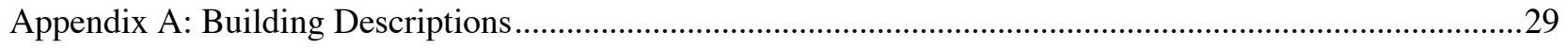

Appendix B: Flowchart for Auditing Desktop Computer Power State ..........................................................31

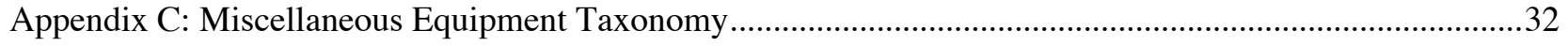

Appendix D: Miscellaneous Equipment Numbers, by Category and Site.........................................................33

LBNL-53729-Revised $\quad$ i 


\section{List of Tables}

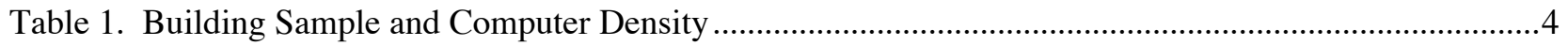

Table 2. Office and Miscellaneous Equipment: Number of Units and Density ...............................................

Table 3. Office Equipment: After-hours Power States....................................................................................

Table 4. Ratio of Laptop to Desktop Computers at Two Sites .......................................................................11

Table 5. Analysis of Monitor Power Management by Computer Power State …............................................11

Table 6. Number and Percent of LCD Monitors, by Site .............................................................................13

Table 7. Office Equipment Turn-off and Power Management Rates .............................................................16

Table 8. Total Energy Consumption of Miscellaneous Equipment, by Category ……….................................20

Table 10. Top 50 Miscellaneous Equipment Types, by Total Energy Consumption........................................23

\section{List of Figures}

Figure 1. Comparison of LBNL and CBECS Commercial Building Samples ..................................................

Figure 2. Office and Miscellaneous Equipment Density, by Building Type (and number) ..............................8

Figure 3. Office Equipment Power States.................................................................................................. 10

Figure 4. Monitor After-hours Power Status, by Building Type …................................................................13

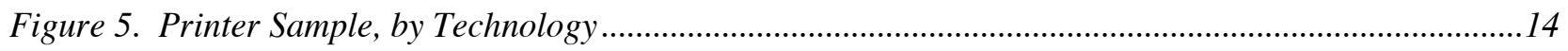

Figure 6. Laser Printers: Powersave Delay Settings ................................................................................ 14

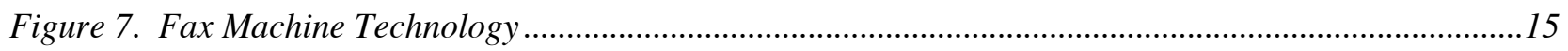

Figure 8. Miscellaneous Equipment Numbers, by Category and Building Type ..........................................18

Figure 9. Miscellaneous Equipment Density, per $1000 \mathrm{ft}^{2}$ Floor Area …...................................................18

Figure 10. TEC of Miscellaneous Equipment, Normalized by Floor Area $\left(\mathrm{kWh} / \mathrm{yr}\right.$ per $\left.1000 \mathrm{ft}^{2}\right)$..................21

Figure 11. TEC of Miscellaneous Equipment, as Percent of Building Type ……..........................................21

Figure 12. End-Use Breakdown of Top 50 Miscellaneous Equipment Types, by TEC...................................24

Figure 13. External Power Supplies: Number, Type and Frequency …….................................................24 


\section{Abbreviations, Acronyms, and Glossary of Terms}

\section{As Used in This Report}

CRT cathode ray tube (monitor)

CPU central processing unit

ICS integrated computer system, in which computer and monitor share a power cord, (e.g., an LCD monitor powered through a computer) and may also share a housing (e.g., an Apple iMac)

ILPS in-line power supply: a type of external power supply found on the cord between the plug and the device; aka "fat snake" because it looks like the power cord swallowed a box or cylinder

LBNL Lawrence Berkeley National Laboratory (aka LBL or Berkeley Lab)

LCD liquid crystal display (monitor)

ME miscellaneous (plug-load) equipment

MFD multi-function device: a unit of digital equipment that can perform at least two of the following functions: copy, fax, print, scan

OE office equipment

OEM original equipment manufacturer

OS operating system (e.g., Windows XP or Mac OS X)

PC personal computer: a generic term that includes laptop computers, desktop computers and integrated computer systems; it includes both Apple and Intel-architecture machines

PDA personal digital assistant; a cordless (i.e., rechargeable) hand-held computer device

PIPS plug-in power supply: a type of external power supply that is incorporated into the cord's plug; aka "wall wart"

PM power management: the ability of electronic equipment to automatically enter a low power mode or turn itself off after some period of inactivity; PM rate is the percent of units not off that are in low power.

PM rate: the extent to which a given sample or type of equipment is actually found to have automatically entered a low power mode or turned itself off.

PM Enabling rate: the extent to which settings in the user interface of a given sample or type of equipment indicate the equipment is set to automatically enter low power or turn itself off.

XPS external power supply: a power supply external to the device that it powers; a voltage regulating device incorporated into either the power cord or the wall plug of a device 


\section{Acknowledgements}

This study would not have been possible without the support of the ENERGY STAR Office Equipment and Commercial Buildings programs, as well as the cooperation of the owners and facility managers of the businesses, institutions, and organizations that participated, and whose anonymity we promised to maintain.

We would like to thank our reviewers:

Jim McMahon, Bruce Nordman, David Fridley and Steve Greenberg of LBNL;

Kent Dunn and Michael Thelander of Verdiem: Energy Efficiency for PC Networks, Seattle WA; and Terry O'Sullivan of Energy Solutions, Oakland CA. 


\title{
After-hours Power Status of Office Equipment and Inventory of Miscellaneous Plug-Load Equipment
}

\author{
Judy A. Roberson, Carrie A. Webber, Marla C. McWhinney, \\ Richard E. Brown, Margaret J. Pinckard, and John F. Busch
}

\begin{abstract}
This research was conducted in support of two branches of the EPA ENERGY STAR program, whose overall goal is to reduce, through voluntary market-based means, the amount of carbon dioxide emitted in the U.S. The primary objective was to collect data for the ENERGY STAR Office Equipment program on the afterhours power state of computers, monitors, printers, copiers, scanners, fax machines, and multi-function devices. We also collected data for the ENERGY STAR Commercial Buildings branch on the types and amounts of "miscellaneous" plug-load equipment, a significant and growing end use that is not usually accounted for by building energy managers. For most types of miscellaneous equipment, we also estimated typical unit energy consumption in order to estimate total energy consumption of the miscellaneous devices within our sample. This data set is the first of its kind that we know of, and is an important first step in characterizing miscellaneous plug loads in commercial buildings.

The main purpose of this study is to supplement and update previous data we collected on the extent to which electronic office equipment is turned off or automatically enters a low power state when not in active use. In addition, it provides data on numbers and types of office equipment, and helps identify trends in office equipment usage patterns. These data improve our estimates of typical unit energy consumption and savings for each equipment type, and enables the ENERGY STAR Office Equipment program to focus future effort on products with the highest energy savings potential.

This study expands our previous sample of office buildings in California and Washington DC to include education and health care facilities, and buildings in other states. We report data from sixteen commercial buildings in California, Georgia, and Pennsylvania: four education buildings, two medical buildings, two large offices ( $>500$ employees each), three medium offices (50-500 employees each), and five small business offices (<50 employees each). Two buildings are in the San Francisco Bay area of California, nine (including the five small businesses) are in Pittsburgh, Pennsylvania, and five are in Atlanta, Georgia.
\end{abstract}




\section{Introduction}

Since the 1980s there has been continual growth in the market for electronic office equipment, particularly personal computers and monitors, but also printers and multi-function devices, which are replacing discrete copiers, fax machines and scanners in some office environments. According to 2003 projections by the Department of Energy, annual energy use by personal computers is expected to grow 3\% per year, and energy use among other types of office equipment is expected to grow $4.2 \%$; this growth is in spite of improvements in energy efficiency, which are expected to be offset by "continuing penetration of new technologies and greater use of office equipment" (EIA 2003).

In 1992 the US Environmental Protection Agency (EPA) launched the voluntary ENERGY STAR program, designed to curb the growth of $\mathrm{CO}_{2}$ emissions by labeling the most energy-efficient electronic products for the mutual benefit of manufacturers, consumers, and the environment. ${ }^{1}$ The first products to be labeled were computers and monitors; printers were added in 1993, fax machines in 1994, copiers in 1995, and scanners and multi-function devices in 1997 (EPA/DOE 2003). Continued improvement in energy savings among office equipment remains a focus of the ENERGY STAR program, which updates its product specifications as necessary to respond to changes in technology, energy consumption, and usage patterns.

ENERGY STAR labeled office equipment reduces energy use primarily through power management (PM), in which equipment is factory-enabled to automatically turn off or enter low power (any power level between off and on) after some period of inactivity, usually 15 or 30 minutes. Most office equipment is idle more often than it is active; among equipment that users tend to leave on when not in use, such as shared and networked devices, PM can save significant energy. ENERGY STAR devices have a large market share, but the percentage that actually power manage is lower for several reasons. Power management is sometimes delayed or disabled by users, administrators, or even software updates that change the factory settings in the interface; in addition, some network and computing environments (e.g., the Windows NT operating system) effectively prevent PM from functioning.

To accurately estimate energy savings attributable to the ENERGY STAR program, and target future efforts, current data are needed on the extent to which each type of office equipment is turned off or successfully enters low power mode when idle. Combined with measurements of the energy used in each power state, we can estimate typical unit energy consumption (UEC), which, combined with number of units currently in use, provides an estimate of total energy use, and program savings (Webber, Brown et al. 2002).

In our ongoing technical support of the ENERGY STAR program, the Energy Analysis Department at Lawrence Berkeley National Lab (LBNL) has conducted after-hours surveys (aka night-time audits) of office equipment in commercial buildings. Our previous series of surveys was conducted during the summer of 2000; it included nine buildings in the San Francisco Bay area and two in the Washington DC area. We recruited and surveyed a diversity of office types and documented just over 100 computers per site, on average. We collected data on the types, power states and PM delay settings of ENERGY STAR labeled office equipment (computers, monitors, copiers, fax machines, printers, scanners and multi-function devices). The methods and results of that study were reported previously (Webber, Roberson et al. 2001).

\footnotetext{
1 The ENERGY STAR ${ }^{\circledR}$ program has expanded to include residential appliances and heating and cooling equipment, consumer electronics, building materials and components, refrigeration equipment, commercial buildings and new homes. Since 1996 it has been jointly administered by the U.S. EPA and DOE (http://energystar.gov/).
} 
In that study we also recorded (but did not report) numbers of some 'miscellaneous office equipment,' such as computer speakers, external disk drives, portable fans and heaters, boomboxes, and battery chargers.

In this report, we present the results of our most recent (2003) after-hours survey of commercial buildings, which expanded on the previous study to include:

- buildings in Pittsburgh, Pennsylvania and Atlanta, Georgia,

- education buildings, health care buildings, and small offices, and

- an inventory of miscellaneous plug-load equipment.

As part of our ongoing effort to improve the accuracy of data used to evaluate the ENERGY STAR program, we wanted to capture data from a wider range of commercial building types and geographic regions. While our sample is not large enough to distinguish regional differences in equipment night-time or after-hours power status, we hope to improve the robustness of our data by increasing its geographic diversity. Also, because office equipment is not confined to offices or office buildings, we wanted to capture data from other types of commercial buildings, such as schools, which also have significant numbers of computers.

Collecting data on after-hours power status involves visiting buildings when most employees are gone. Given the difficulty of arranging after-hours access to most commercial buildings, we used this opportunity to simultaneously collect data for the ENERGY STAR Commercial Buildings program on the types and numbers of miscellaneous plug-load equipment, and to develop a taxonomy by which to categorize them. These data allow us to begin to better characterize the large 'plug-load' building energy end use category.

\section{Methodology}

The protocol used in this series of surveys changed from that of 2000 because of the need to develop a data collection protocol for miscellaneous equipment, and then integrate it with our office equipment protocol.

\section{Building Sample}

Table 1 below outlines the buildings in our sample, which are identified by a letter; for this purpose the small businesses are aggregated into one 'small office.' Appendix A describes them in more detail, but only in generic terms, to preserve the anonymity of occupants. As in 2000, our initial target was to collect data on at least 1,000 computers. In selecting types and numbers of commercial buildings to comprise that sample, we referred to data on computer densities provided by the Commercial Building Energy Consumption Survey (CBECS) (EIA/CBECS 2002). According to CBECS, in 1999, 74\% of the U.S. population of computers were found among office, education, and health care buildings; therefore, our building recruitment effort focused on these three types of buildings. CBECS further characterizes offices by number of employees: 0-19 (small), 20-499 (medium), and 500+ (large).

To familiarize ourselves with what to expect (in recruitment effort and equipment found) in schools and health care buildings, we began by surveying a high school and a medical clinic in the San Francisco area. We then recruited and surveyed a variety of buildings in Pittsburgh in April, and Atlanta in June 2003.

Site recruitment is one of the most difficult and time consuming aspects of commercial building surveys. Usually it involves cold-calling from a list of prospective business or building types (e.g., high schools), briefly describing our research activity, and trying to connect with the person who is able and willing to grant after-hours access, which involves providing a key and/or escort. Most facilities have real concerns about safety, security, and privacy (e.g., of client or patient records), which of course must be addressed. 
In each building, we surveyed as much area as possible in four hours or until we covered the area accessible to us, whichever came first. At two sites we surveyed a single floor, at four sites we surveyed the entire space available to us, and at the remaining six sites we surveyed portions of two or three floors. In general, the greater the density and variety of equipment found, the less area we covered in four hours. Floor areas are approximate gross square feet, based on floor plans or information from facility managers.

Table 1. Building Sample and Computer Density

\begin{tabular}{|c|c|c|c|c|c|c|c|c|}
\hline \multirow{2}{*}{ site } & \multirow{2}{*}{ state } & \multirow{2}{*}{ building type } & \multirow{2}{*}{ occupancy } & \multicolumn{3}{|c|}{ in area surveyed (approximate no.) } & \multicolumn{2}{|c|}{ computer density per } \\
\hline & & & & computers & $\mathrm{ft}^{2}$ & employees & $1000 \mathrm{ft}^{2}$ & employee \\
\hline $\mathbf{A}$ & GA & education & university classroom bldg & 171 & 28,000 & $\mathrm{n} / \mathrm{a}$ & 6.1 & $\mathrm{n} / \mathrm{a}$ \\
\hline B & PA & medium office & non-profit headquarters & 182 & 55,000 & 128 & 3.3 & 1.42 \\
\hline $\mathbf{C}$ & GA & large office & corporate headquarters & 262 & 28,000 & 120 & 9.4 & 2.18 \\
\hline D & $\mathrm{CA}$ & education & high school & 112 & 40,000 & $\mathrm{n} / \mathrm{a}$ & 2.8 & $\mathrm{n} / \mathrm{a}$ \\
\hline $\mathbf{E}$ & GA & medium office & business consulting firm & 37 & 22,000 & 70 & 1.7 & 0.53 \\
\hline $\mathbf{F}$ & PA & education & high school & 248 & 100,000 & $\mathrm{n} / \mathrm{a}$ & 2.5 & $\mathrm{n} / \mathrm{a}$ \\
\hline $\mathbf{G}$ & $\mathrm{CA}$ & health care & outpatient clinic & 177 & 45,000 & $\mathrm{n} / \mathrm{a}$ & 3.9 & $\mathrm{n} / \mathrm{a}$ \\
\hline $\mathbf{H}$ & GA & medium office & information services dept & 153 & 24,000 & 76 & 6.4 & 2.01 \\
\hline $\mathbf{J}$ & PA & health care & private physicians' offices & 56 & 26,000 & $\mathrm{n} / \mathrm{a}$ & 2.2 & $\mathrm{n} / \mathrm{a}$ \\
\hline $\mathbf{K}$ & PA & small office & 5 small businesses combined & 117 & 20,000 & 77 & 5.9 & 1.52 \\
\hline $\mathbf{M}$ & PA & large office & corporate headquarters & 73 & 40,000 & 125 & 1.8 & 0.58 \\
\hline \multirow[t]{2}{*}{$\mathbf{N}$} & GA & education & university classroom bldg & 95 & 20,000 & $\mathrm{n} / \mathrm{a}$ & 4.8 & $\mathrm{n} / \mathrm{a}$ \\
\hline & & & total & 1,683 & 448,000 & \multicolumn{3}{|c|}{$\mathrm{n} / \mathrm{a}=$ not available } \\
\hline
\end{tabular}

Our characterization of offices differs slightly from that of CBECS. By our definition a small office has $<50$ employees, a medium office has 50-500 employees, and a large office has >500 employees on site. Also, CBECS appears to classify offices by the number of employees per building, while we classify them by the number of employees per location. For example, our site E is a 'medium office' (50-500 employees) that occupies one floor of a high-rise office tower; however, CBECS might consider the same office to be part of a 'large office' (over 500 employees) that includes all offices within the entire building.

Our 'small office' is actually aggregated results for five small businesses in three different buildings: (1) a graphics and printing business, (2) an environmental consulting firm, (3) a commodity brokerage firm, (4) a software development firm, and (5) an engineering firm. Their number of employees ranged from 4 to 25 , with a collective total of 77 employees.

For the six offices in our sample, Table 1 also shows the approximate density of computers by gross square feet as well as per employee. We do not have number of employees (or computer density per employee) for education and medical facilities. For high schools, where the number of students is known, equipment density per student could be a useful metric if we had surveyed the entire building, which we did not. The number of students regularly using a university classroom building, as well as the number of employees in both education and medical buildings is much more variable and difficult to determine.

Although we used the CBECS data as a starting point in our building selection and recruitment efforts, our resulting building sample does not necessarily correspond to the much larger CBECS building sample. Figure 1 below compares our building sample to CBECS, based on the sum of floor area surveyed and number of computers found among all office, education, and health care buildings in each sample. Compared to CBECS, offices are somewhat under-represented in our current sample, while education and health care buildings are somewhat over-represented. In addition, new buildings and high schools may be over-represented in our building sample, though we don't have corresponding CBECS data for comparison. 
Figure 1. Comparison of LBNL and CBECS Commercial Building Samples
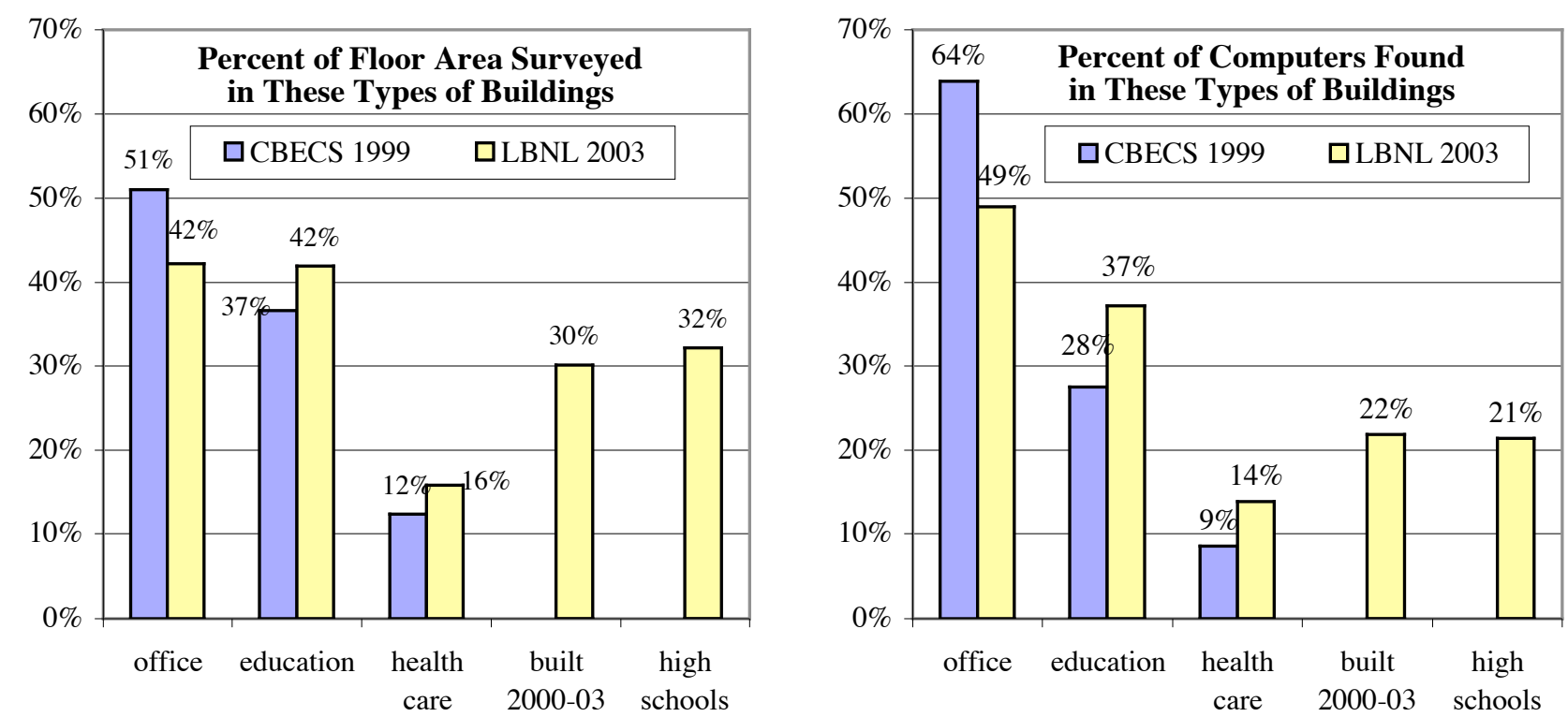

\section{Survey Protocol}

Each survey takes four people up to four hours to complete, and occurs on a weekday evening or weekend. We usually work in two teams of two people, with one calling out information and the other recording it. Using a floor plan, clipboard, flashlight and tape measure, we systematically record each plug-load device. The flashlight helps in tracing cords to plugs, and the tape is used to measure TV and monitor screen sizes. Our data collection is as unobtrusive as possible; we don't turn computers on or off or access any programs, settings, or files. If a workspace is occupied or obviously in use, we skip it and return later, if possible.

\section{Office Equipment Data Collection}

For our purposes in this study, office equipment includes the following equipment categories and types:

- computers: desktop, laptop (notebook or mobile), server, and integrated computer system (ICS);

- monitors: cathode ray tube (CRT), and liquid crystal display (LCD);

- $\quad$ printers: impact, inkjet, laser, thermal, solid ink, and wide format;

- fax machines: inkjet, laser, and thermal;

- copiers;

- $\quad$ scanners: document, flatbed, slide, and wide format; and

- multi-function devices: inkjet and laser.

For each unit of office equipment, we recorded the make (brand) and model as it appears on the front or top of the unit (we did not record information from the nameplate on the bottom or back of the unit). We recorded the diagonal measurement, to the nearest inch, of monitor screens, except those of laptops (note: for CRT monitors this measurement is smaller than the nominal screen (or tube) size). For laser printers and MFDs we scrolled through the menu options available in the user interface to find the "power save delay setting," which usually ranges from 15 minutes to "never."

We tried to record each unit of office equipment that had an external power supply (XPS). These devices offer significant potential for energy efficiency improvement because they draw power even when the unit of which they are part is turned off or disconnected (e.g., when a laptop computer or cell phone is removed 
from its charger, which remains plugged in). We distinguish two types of external power supply: a plug-in power supply (PIPS), in which an AC/DC voltage transformer is incorporated into the plug, and an in-line power supply (ILPS), which is incorporated into and appears as an enlarged part of the power cord. We also tried to record whether or not each printer, copier, and MFD was connected to a network via cable (to the extent that networks become wireless, network connection will become more difficult to determine).

The power state of each unit was recorded as on, low, off, or unplugged (exception: we did not record units that were unplugged if it appeared they were never used). Although some office equipment, particularly copiers, may have features that enable them to turn off automatically or enter low power manually (by user action), we assume that the vast majority of units found off were turned off manually (i.e., by a user) and that units found in low power entered that state automatically (i.e., without user action).

If a monitor/computer pair were both on, we recorded the screen content; the most common occurrences are a screensaver, application, log-in or other dialog box (e.g., "It is now safe to turn off your computer"). When a monitor is off and the computer to which it is connected is not, it can be difficult to tell whether the computer is on or in low power. The method we used to determine a PC's power state is outlined in Appendix B; in short, a clampmeter is used to measure relative current in the computer power cord before and after initiating a computer wake function, such as touching the mouse or keyboard (McCarthy, 2002).

The power state of a laptop computer is usually difficult to determine, unless it is in use and obviously on. A closed laptop has few external indicators, and those that are present are often ambiguous and inconsistent (e.g., between brands or models). In terms of improving our estimates of laptop unit energy consumption, the most relevant data are the amount of time each laptop spends plugged in, and how often its battery is (re)charged. Therefore, we recorded, at a minimum, whether or not each laptop was plugged in.

In this report the term 'computer workstation' refers to any combination of computer(s) and monitor(s) physically used by one person at a time; generally, there is a workstation associated with each office chair. Workstation configurations vary widely; most common is one desktop computer connected to one monitor, but we have noticed growing numbers of other configurations, including multiple computers with one monitor, multiple (usually LCD) monitors with one computer, and laptops used with a docking station and monitor. In this series of surveys, we identified each computer workstation by a unique number; i.e., all components of each workstation were identified by the same number. We did this for two reasons: first, to facilitate subsequent analysis of the relationship between computer and monitor power states; and second, to be able to characterize the variety of workstations found. These analyses are discussed in the Results.

\section{Miscellaneous Equipment Data Collection}

'Miscellaneous equipment' (ME) refers to plug-load devices whose energy use is not usually accounted for by building energy managers because they are portable, often occupant-provided units whose number, power consumption and usage patterns are largely unknown. All ME in this report, including lighting, is plug-load, as opposed to hard-wired, although for some equipment (e.g., commercial refrigerators) we did assume a plug. The sheer variety of ME necessitates development of a taxonomy by which it can be categorized and summarized. Appendix $\mathrm{C}$ presents our current miscellaneous equipment taxonomy.

For each unit of miscellaneous equipment we recorded any information (e.g., power state or rated power) that could be used to estimate unit energy consumption. For lighting we recorded lamp type (e.g., halogen), wattage, and fixture type (desk, floor, track, etc.). For battery chargers, we noted the portable component (drill, oto-opthalmoscope, walkie-talkie. etc.) and whether the charger was empty or full. For vending machines, we recorded temperature and product (e.g., cold beverage) and any lighting. For unknown equipment we noted make and model for later determination of identity and power specifications. 
As with office equipment, we noted if there was a PIPS or ILPS. We also recorded PIPSs and ILPSs that were plugged in but unattached to equipment (such as a PIPS used to charge an absent cell phone) and those whose equipment could not be identified, such as among a maze of cords in a server room. Nevertheless, we undoubtedly missed some, so our reported number of PIPSs and ILPSs is actually a conservative estimate.

\section{Limitations of This Methodology}

One advantage of conducting after-hours building walk-throughs to collect data on office equipment power status is that a good variety and number of buildings can be recruited and surveyed. On the other hand, the data collected represent a snapshot in time, and do not capture variations in user behavior over time, which would require automated long-term time series metering of equipment power state and power levels.

This is our most robust sample of buildings to date for collecting data on the after hours power status of office equipment. It includes data on 1,683 computers (including desktops, ICSs, laptops and servers) and about 448,000 $\mathrm{ft}^{2}$ in 12 commercial buildings, including schools and health care facilities in California, Georgia, and Pennsylvania. (In comparison, our previous (2000) survey included 1,280 computers in 11 office buildings in California and Washington DC.) However, we do not suggest that this sample is representative of commercial buildings as a whole or in part (e.g., by type, size, age, or location), or that the results presented here are statistically significant. It is a record of what we found that we hope will be of use to policy makers, researchers, and building managers.

\section{Results and Discussion}

\section{Equipment Density}

Table 2 shows the number and density, per 1000 approximate gross square feet, of office equipment, miscellaneous equipment, and the sum of $\mathrm{OE}$ and $\mathrm{ME}$ in each building, and for all buildings. Our survey captured data on over 10,000 units of equipment, including almost 4,000 units of office equipment.

Table 2. Office and Miscellaneous Equipment: Number of Units and Density sorted by Density of Office Equipment (units/1000 $\mathrm{ft}^{2}$ )

\begin{tabular}{|c|c|c|c|c|c|c|c|c|c|c|}
\hline \multirow[b]{2}{*}{ bldg type } & \multirow[b]{2}{*}{ site } & \multicolumn{3}{|c|}{ Number of Units } & \multicolumn{3}{|c|}{ Density (units/1000 ft ${ }^{2}$ ) } & \multicolumn{3}{|c|}{ Density (units/employee) } \\
\hline & & $\mathbf{O E}$ & ME & OE+ME & OE & ME & OE+ME & $\mathbf{O E}$ & ME & OE+ME \\
\hline medium office & $\mathbf{E}$ & 98 & 441 & 539 & 4.5 & 20.0 & 24.5 & 1.4 & 6.3 & 7.7 \\
\hline education & $\mathbf{F}$ & 574 & 596 & 1,170 & 5.7 & 6.0 & 11.7 & & & \\
\hline large office & M & 227 & 753 & 980 & 5.7 & 18.8 & 24.5 & 1.8 & 6.0 & 7.8 \\
\hline education & D & 258 & 291 & 549 & 6.5 & 7.3 & 13.7 & & & \\
\hline health care & $\mathbf{J}$ & 171 & 458 & 629 & 6.6 & 17.6 & 24.2 & & & \\
\hline medium office & B & 410 & 422 & 832 & 7.5 & 7.7 & 15.1 & 3.2 & 3.3 & 6.5 \\
\hline education & $\mathbf{N}$ & 204 & 234 & 438 & 10.2 & 11.7 & 21.9 & & & \\
\hline health care & G & 460 & 1,002 & 1,462 & 10.2 & 22.3 & 32.5 & & & \\
\hline education & A & 377 & 259 & 636 & 13.5 & 9.3 & 22.7 & & & \\
\hline small office & $\mathbf{K}$ & 275 & 528 & 803 & 13.8 & 26.4 & 40.2 & 3.6 & 6.9 & 10.4 \\
\hline medium office & $\mathbf{H}$ & 340 & 630 & 970 & 14.2 & 26.3 & 40.4 & 4.5 & 8.3 & 12.8 \\
\hline large office & C & 540 & 612 & 1,152 & 19.3 & 21.9 & 41.1 & 4.5 & 5.1 & 9.6 \\
\hline all buildings & & 3,934 & 6,226 & 10,160 & 8.8 & 13.9 & 22.7 & 3.2 & 5.7 & 8.9 \\
\hline
\end{tabular}


Note that the numbers of miscellaneous equipment units in Table 2 are lower than those in Appendix D because Table 2 does not include plug-in and in-line power supplies, while Appendix D does.

Figure 2 illustrates office and miscellaneous equipment density (per 1000 square feet), by building type.

Figure 2. Office and Miscellaneous Equipment Density, by Building Type (and number)

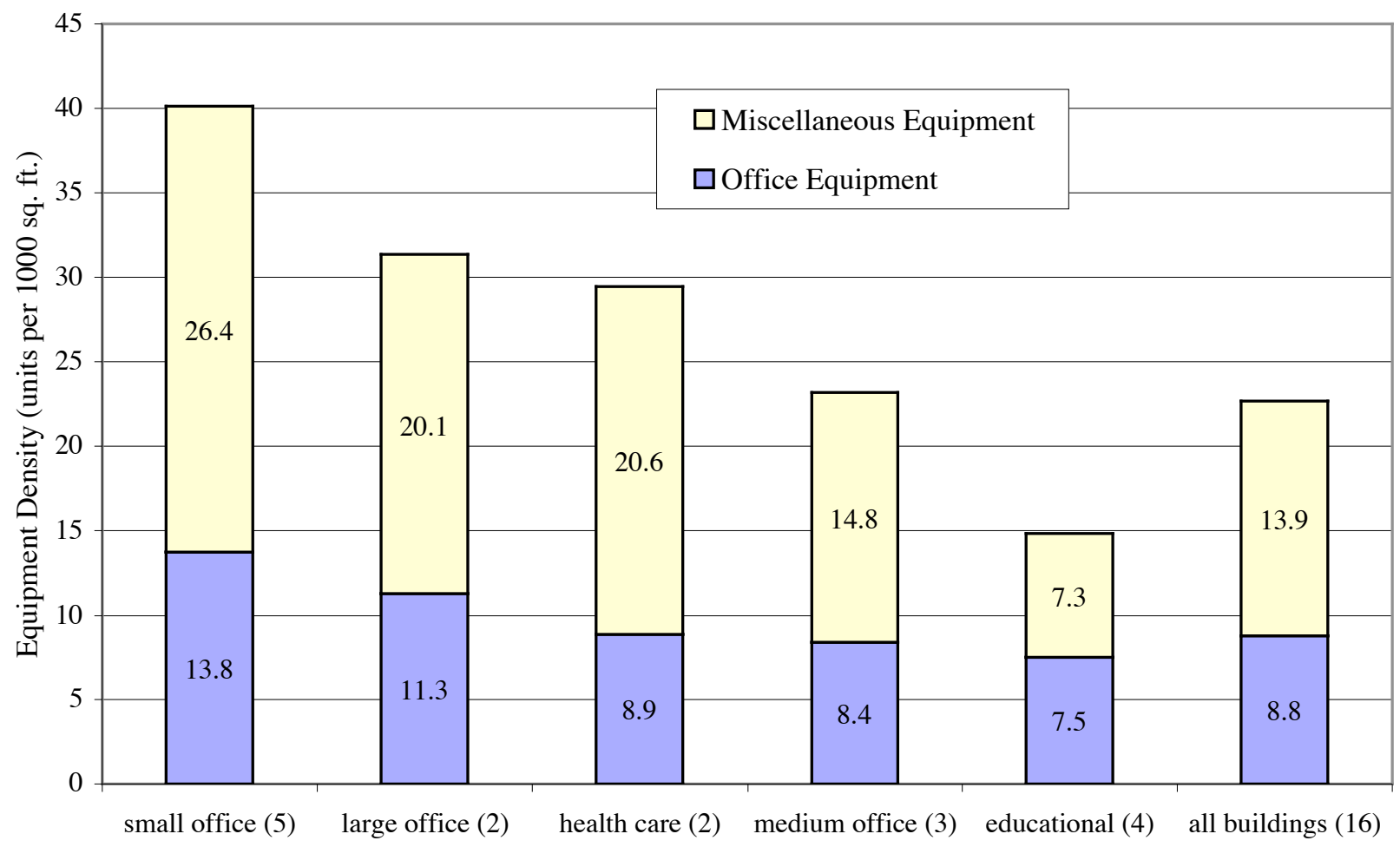

From Table 2 we see that the two buildings with the lowest combined equipment density are high schools, and Figure 2 shows that education buildings in our sample had the lowest equipment densities overall. Among our sample of 12 buildings, building types with the highest densities are small and large offices. We suggest that small offices may have high equipment density because every office needs certain devices (e.g., copier, fax machine, microwave oven, refrigerator), regardless of how many (or few) people share it. Medium offices exhibited a range of density (see Table 2, sites B, H), but on average their office equipment density is similar to and their miscellaneous equipment density is lower than that of health care facilities.

Closer examination of the results for each building reveals some underlying trends. For example, the only two buildings with a computer density less than 2 per $1000 \mathrm{ft}^{2}$ (from Table 1) were offices (one medium, one large) whose employees tend to rely on laptop computers, most of which were absent during our visit; one of these companies requires employees to take their laptops home or lock them up when not at work.

\section{Office Equipment}

Our sample includes data on the power state of 1,453 desktop computers (well above our target of 1,000), 1,598 monitors, 353 printers, 89 servers, 79 MFDs, 47 fax machines, 45 ICSs, 34 scanners, and 33 copiers. Among printers, our discussion of results will focus on the 158 laser and 123 inkjet printers found. 
Among all buildings, computer density ranges from 1.7 to 9.4 per $1000 \mathrm{ft}^{2}$ gross floor area, (see Table 1). Among office buildings only, computer density ranges from 0.53 to 2.18 per employee. Office equipment density ranges from 4.5 to 19.3 units per $1000 \mathrm{ft}^{2}$ gross floor area, with an average of 8.8 (see Table 2). Among offices, office equipment density ranges from 1.4 to 4.5 units per employee, with an average of 3.2.

When analyzing the numbers of equipment in each power state, we are primarily interested in two values: turn-off rates and power management rates. 'Turn-off rate' is the percent of each equipment type that is turned off, while 'PM rate' is the percent of those not off that are in low power.

Table 3 shows the numbers of each type of office equipment, and their after-hours power state. Table 3 does not include laptop computers, units that were unplugged, or units whose power state was unknown.

Table 3. Office Equipment: After-hours Power States

\begin{tabular}{|c|c|c|c|c|c|c|c|c|c|}
\hline \multicolumn{2}{|c|}{ Equipment } & \multicolumn{4}{|c|}{ Number } & \multicolumn{4}{|c|}{ Percent } \\
\hline \multirow{4}{*}{$\begin{array}{l}\text { Category } \\
\text { computers }\end{array}$} & Type & on & low & off & sum & on & low & off & PM rate \\
\hline & desktop & 869 & 60 & 524 & 1453 & $60 \%$ & $4 \%$ & $36 \%$ & $6 \%$ \\
\hline & server & 87 & & 2 & 89 & $98 \%$ & $0 \%$ & $2 \%$ & $\mathrm{n} / \mathrm{a}$ \\
\hline & ICS & 7 & 11 & 27 & 45 & $16 \%$ & $24 \%$ & $60 \%$ & $61 \%$ \\
\hline \multirow[t]{2}{*}{ monitors } & CRT & 259 & 648 & 422 & 1329 & $19 \%$ & $49 \%$ & $32 \%$ & $71 \%$ \\
\hline & LCD & 56 & 164 & 49 & 269 & $21 \%$ & $61 \%$ & $18 \%$ & $75 \%$ \\
\hline \multirow[t]{6}{*}{ printers } & laser & 53 & 81 & 24 & 158 & $34 \%$ & $51 \%$ & $15 \%$ & $60 \%$ \\
\hline & inkjet & 86 & & 37 & 123 & $70 \%$ & $\mathrm{n} / \mathrm{a}$ & $30 \%$ & $\mathrm{n} / \mathrm{a}$ \\
\hline & impact & 16 & & 6 & 22 & $73 \%$ & $\mathrm{n} / \mathrm{a}$ & $27 \%$ & $\mathrm{n} / \mathrm{a}$ \\
\hline & thermal & 31 & & 7 & 38 & $82 \%$ & $\mathrm{n} / \mathrm{a}$ & $18 \%$ & $\mathrm{n} / \mathrm{a}$ \\
\hline & wide format & 2 & & 6 & 8 & $25 \%$ & $0 \%$ & $75 \%$ & $0 \%$ \\
\hline & solid ink & 1 & 3 & & 4 & $25 \%$ & $75 \%$ & $0 \%$ & $75 \%$ \\
\hline \multirow[t]{2}{*}{ MFDs } & inkjet & 9 & 4 & 3 & 16 & $56 \%$ & $25 \%$ & $19 \%$ & $31 \%$ \\
\hline & laser & 36 & 14 & 13 & 63 & $57 \%$ & $22 \%$ & $21 \%$ & $28 \%$ \\
\hline copiers & all & 12 & 5 & 16 & 33 & $36 \%$ & $15 \%$ & $48 \%$ & $29 \%$ \\
\hline fax machines & all & 44 & 3 & & 47 & $94 \%$ & $6 \%$ & $0 \%$ & $6 \%$ \\
\hline scanners & all & 8 & 12 & 14 & 34 & $24 \%$ & $35 \%$ & $41 \%$ & $60 \%$ \\
\hline
\end{tabular}

Not surprisingly, turn-off rates were lowest among fax machines and server computers. Turn-off rates were highest for integrated computer systems (60\%), copiers (48\%), and scanners $(41 \%)$. PM rates were highest among LCD monitors (75\%), CRT monitors (71\%), ICSs (61\%), scanners (60\%), and laser printers (60\%).

The lowest power management rates were among desktop computers and fax machines (6\% of each). Because copiers and MFDs often have long (2-4 hour) PM delay settings that may not have elapsed at the time of our visit, PM rates in Table 3 for this equipment should be considered a minimum or lower bound. Figure 3 (below) graphically shows the breakdown by power state of each major type of office equipment.

\section{Computers}

We categorized computers as either desktop, integrated computer systems, servers, or laptops. Among 1,453 desktop computers the turn-off rate was 36\%; it ranged from 5\% (at Site E, medium office) to $67 \%$ (at Site B, medium office). Only 6\% of all desktop computers that were not off were in low power. This PM rate is similar to the $5 \%$ rate found in a previous study (Webber, Roberson et al. 2001). Among the 45 ICSs in Table 3 the turn-off rate was $60 \%$, and the PM rate was $61 \%$. However, it is possible that of the 11 ICSs found in low power, only the display (but not the CPU) was in low power. 
Figure 3. Office Equipment Power States

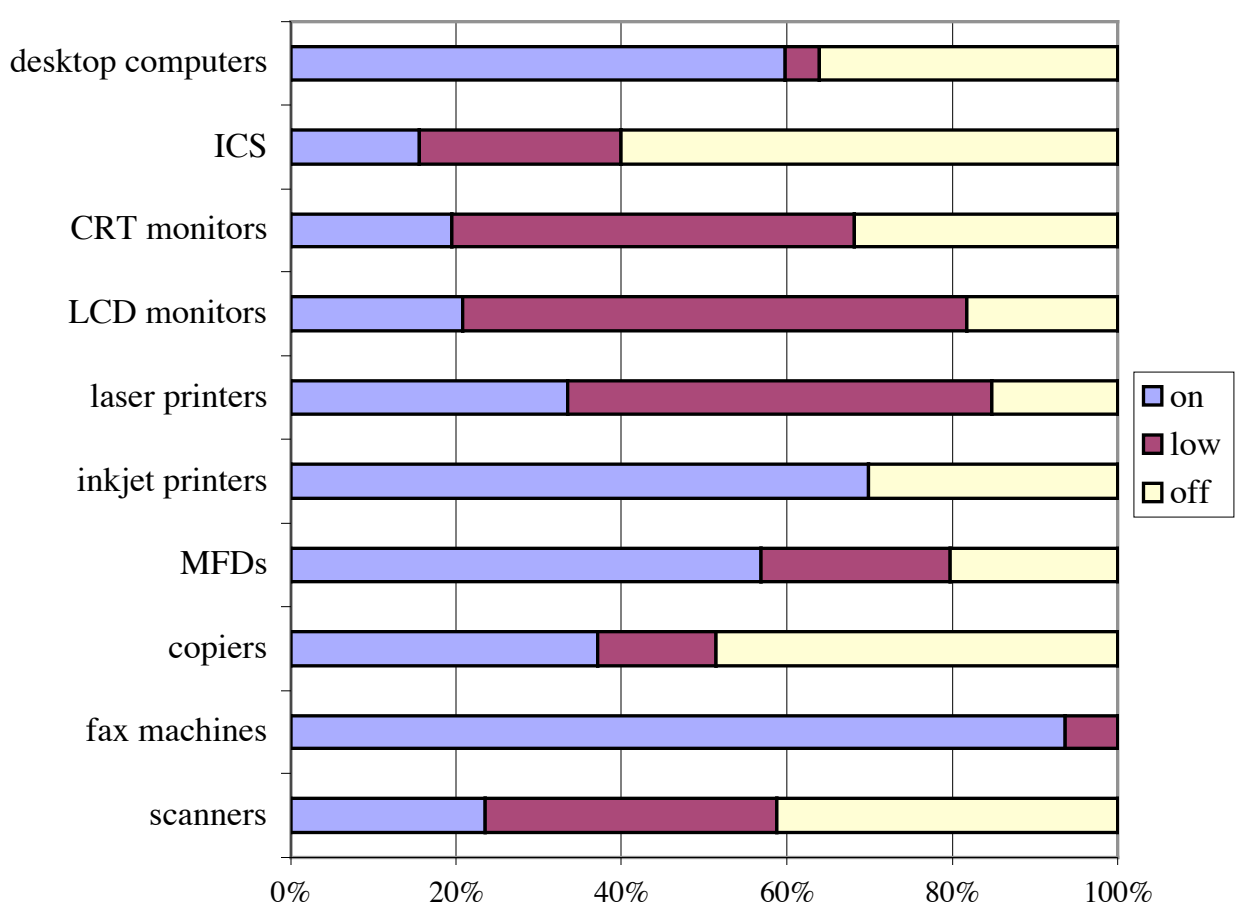

Among education buildings in our sample, the majority of the desktop computers, monitors and ICSs were found in classrooms clearly dedicated to computer-based learning. These "computer labs" typically have a 1:1 ratio between computers and chairs. Among the two high schools, $65 \%$ of desktop computers and ICSs were found in computer labs with at least 15 (and up to 77) computers each; among the two university classroom buildings, 68\% of desktop computers and ICSs were found in computer labs with at least 15 (and up to 57) computers each. Because a single instructor likely controls the after-hours power status of all equipment in these rooms, and also because school buildings in general experience more 'after-hours' per year than other buildings, computer labs present a target for energy-efficiency efforts in schools.

\section{Laptop Computers}

There are 50 laptop computers in our sample, and we recorded information on the power state of 37 . Of those 37, all but two (or 95\%) were plugged in, either through their power cord or a docking station. Nine (or 24\%) of the 37 laptops were clearly on; i.e., their display showed a desktop, application, or login screen.

Sixty percent $(60 \%$, or 21$)$ of the 35 laptops that were plugged in were plugged into docking stations. ${ }^{2}$ Of 107 docking stations found, 20\% (21) were 'full', i.e., contained laptops, while 80\% (86) were 'empty,' or without laptops. Those empty docking stations are evidence of at least 86 more laptops that were absent at the time of our visit. In addition, we found 35 power cords with ILPSs that we identified as "laptop charger, empty" (which we consider in the 'power' category of ME). Combined with 50 laptops and 86 empty docking stations found, we conclude that at least 171 laptop computers are in use among our sample of buildings. Of course, this number does not include (and we did not attempt to estimate) the number of people who take both their laptop and its power cord/battery charger home or lock them up at night.

\footnotetext{
${ }^{2}$ Docking stations are in our 'peripheral' miscellaneous equipment category; laptop computers are office equipment.
} 
If we compare this minimum number of laptop computers to the total number of non-server computers in our sample, from Table 3 (1,453 desktops + 45 ICSs, + 171 laptops = 1669 total), laptops comprise approximately $10 \%$ of non-server computers found in our survey; again, this is a conservative estimate.

Some offices appear to have largely switched from desktop to laptop computers. Table 4 shows that in two (of six) offices in our sample - one large and one medium office - the sum of laptop computers, empty docking stations and empty laptop battery chargers (ILPSs) outnumbered the desktop computers found.

Table 4. Ratio of Laptop to Desktop Computers at Two Sites

\begin{tabular}{|c|c|c|c|c|c|}
\hline \multirow{2}{*}{ Site } & \multirow{2}{*}{$\begin{array}{c}\text { no. of desktop } \\
\text { computers }\end{array}$} & \multicolumn{4}{|c|}{ number of laptop computers } \\
\cline { 3 - 6 } & & laptops found & empty docking stations & empty laptop chargers & estimated total \\
\hline E & $\mathbf{2 0}$ & 4 & 11 & 9 & $\mathbf{2 4}$ \\
M & $\mathbf{4 1}$ & 26 & 40 & 9 & $\mathbf{7 5}$ \\
\hline
\end{tabular}

\section{Monitors}

The average turn-off rate among 1,329 CRT monitors was 32\%; it ranged from $17 \%$ at Site E (medium office) and N (university) to $62 \%$ at Site D (high school). $71 \%$ of CRT monitors that were not off were in low power. Among the 269 LCD monitors in Table 3 the turn-off rate was $18 \%$ and the PM rate was $75 \%$.

Assigning a unique number to each computer/monitor workstation enabled us to analyze the relationship between computer power state and monitor power state. Table 5 shows the results of that analysis. (Note: Table 5 does not include monitors connected to more than one computer.)

Table 5. Analysis of Monitor Power Management by Computer Power State

\begin{tabular}{|c|c|c|c|c|c|c|c|}
\hline \multirow[b]{4}{*}{ Computer } & \multirow[b]{4}{*}{ Computer Power state } & \multirow[b]{4}{*}{ No. } & & & & \multicolumn{2}{|c|}{ Monitor Power Management * } \\
\hline & & & \multirow{2}{*}{\multicolumn{3}{|c|}{ Monitor Power State }} & \multirow{3}{*}{$\begin{array}{l}\text { Monitor PM Rate } \\
\text { (computer is off } \\
\text { or in low power) }\end{array}$} & \multirow{3}{*}{$\begin{array}{c}\text { PC-initiated } \\
\text { Monitor PM Rate } \\
\text { (computer is on ) }\end{array}$} \\
\hline & & & & & & & \\
\hline & & & Off & Low & On & & \\
\hline \multirow[t]{3}{*}{ Desktop } & Off/no signal & 433 & 184 & 244 & 5 & $98 \%$ & \\
\hline & Low & 59 & 4 & 53 & 2 & $96 \%$ & \\
\hline & On & 689 & 154 & 286 & 249 & & $53 \%$ \\
\hline \multirow[t]{2}{*}{ Laptop ** } & Absent or empty docking station & 55 & 13 & 42 & 0 & $100 \%$ & \\
\hline & Plugged-in or in docking station & 23 & 4 & 15 & 4 & $79 \%$ & \\
\hline Server & On & 32 & 14 & 10 & 8 & & $56 \%$ \\
\hline
\end{tabular}

Computers can initiate low power modes in ENERGY STAR monitors. Power management settings in the computer operating system (OS) control panels determine if and when the computer sends a signal to the monitor that causes the monitor to enter low power. If an ENERGY STAR monitor is attached to a computer that is on, it will enter low power only if it receives this signal. "PC-initiated monitor PM rate" refers to the share of systems in which the computer signals the monitor to initiate PM, and the monitor responds. We can infer this rate only among systems in which the computer is on and the monitor is not turned off.

An ENERGY STAR monitor can also enter low power if there is no video signal from the computer, either because the computer is off, it is in low power, or the monitor is disconnected from the computer. "Monitor $\mathrm{PM}$ rate" refers to the share of monitors that power manage in the absence of a signal from the computer.

Among monitors that were not turned off, those connected to computers that were off or absent had monitor power management rates of $98 \%$ (with desktop computers) and 100\% (with laptops); monitors not 
off and connected to desktop computers that were in low power had a 96\% monitor PM rate. In the remaining cases, the monitor may have been incapable of power managing (i.e., it was non-ENERGY STAR). Monitors not off and connected to desktop or server computers that were on had PC-initiated monitor PM rates that were much lower: 53\% (for desktop computers) and 56\% (for servers). Clearly, monitors that depended on a computer signal to initiate power management were much less likely to enter low power.

In our 2000 study we did not uniquely identify each workstation and so could not conduct this analysis. However, our 2003 monitor "PC-initiated PM rate" differs from the monitor "PM enabling rate" of another recent but unpublished study. In 2001, researchers at Energy Solutions in Oakland CA (O'Sullivan 2003) used EZ Save software ${ }^{3}$ to remotely obtain (via local area networks) the PM settings of over 7,000 computer monitors at 17 commercial and institutional sites in the San Francisco Bay area. They found that monitor PM settings in the computer OS control panel were enabled for $44 \%$ of monitors. We would expect the share of monitors that actually power manage when the computer is on to be lower than the share of computers enabled to power manage their monitors (because some monitors may not be ENERGY STAR, there may be network interferences with PM, etc). However, our "PC-initiated PM rate" of 53\% for desktop computers is higher than the 44\% "PM enabling rate" found by Energy Solutions. There are several possible explanations for this:

1) Energy Solutions' 2001 sample contained significantly more computers using the Windows NT OS (which does not support PM and is no longer supported by Microsoft) than LBNL's 2003 sample,

2) Newer computers may be more successful at initiating monitor power management, and newer computer equipment (like newer buildings) may be over-represented in our 2003 sample,

3) Our PC-initiated PM rate is calculated from a subset of monitors (those left on and attached to a PC left on), while Energy Solutions' enabling rate represents all monitors. If turn-off and enabling rates are not independent (i.e., if people who leave their devices on at night are more likely to enable than those who turn their devices off), that could explain part or all of the discrepancy.

4) PC-initiated monitor PM rates actually have risen, as individuals and organizations respond to ENERGY STAR or other educational programs about the energy savings potential of monitor PM, or

5) Our 2003 sample includes a wider variety of commercial building types and locations, and so is more representative than data collected only from office buildings in California,.

In any case, the ability of computers to power manage monitors deserves further scrutiny and improvement.

In the report on our 2000 office equipment field surveys (Webber, Roberson et al. 2001) we speculated that monitors in low power might be thought by users to be off. Among buildings in this report, Site M, a large office, offers anecdotal evidence regarding user (mis)interpretation of monitor power state. According to the facility manager, this company's strict policy is that employees turn their monitors off before leaving, and security personnel turn off any monitors found left on. Our data show that only $4 \%$ of monitors were on, but only $29 \%$ were actually off; the remaining $65 \%$ were in low power mode. This confirms our field observations that if a display is black or blank, users often assume the monitor is off, even though the front panel power indicator (which is amber and/or blinking when the unit is in low power) indicates otherwise.

LCD monitors were not even mentioned in the report on our 2000 field surveys of office equipment, but in 2003, LCDs were 17\% of all monitors. As shown in Table 6, at three sites (including two high schools, D and F) we found no LCD monitors, but at two sites (E, medium office; A, university building), LCD monitors outnumbered CRT monitors, and at three others (B and $\mathrm{H}$, both medium offices; and J, health care) LCDs were over $25 \%$ of all monitors found.

\footnotetext{
${ }^{3}$ EZ Save software was developed by the Department of Energy and adapted by the EPA ENERGY STAR program.
} 
Table 6. Number and Percent of LCD Monitors, by Site sorted by percent of LCD monitors

\begin{tabular}{|c|cccccccccccc|c|}
\hline site & $\mathbf{D}$ & $\mathbf{F}$ & $\mathbf{C}$ & $\mathbf{M}$ & $\mathbf{G}$ & $\mathbf{K}$ & $\mathbf{N}$ & $\mathbf{J}$ & $\mathbf{H}$ & $\mathbf{B}$ & $\mathbf{A}$ & $\mathbf{E}$ & all \\
\hline LCDs & 0 & 0 & 2 & 4 & 12 & 14 & 13 & 18 & 40 & 66 & 96 & 21 & 286 \\
CRTs & 89 & 248 & 254 & 97 & 162 & 88 & 76 & 46 & 104 & 111 & 79 & 12 & 1366 \\
\hline total & 89 & 248 & 256 & 101 & 174 & 102 & 89 & 64 & 144 & 177 & 175 & 33 & 1652 \\
\% LCDs & $0 \%$ & $0 \%$ & $0 \%$ & $4 \%$ & $7 \%$ & $14 \%$ & $15 \%$ & $28 \%$ & $28 \%$ & $37 \%$ & $55 \%$ & $64 \%$ & $17 \%$ \\
\hline
\end{tabular}

While our building sample is not large enough to draw reliable conclusions about office equipment power management based on building type, we did some analysis within our sample. Figure 4 shows the afterhours power status of monitors (both CRT and LCD) based on building type. (A similar analysis for desktop computers and ICSs is not shown here because almost all the computers found in low power were in a single (health care) building, which may be anomalous.)

Figure 4. Monitor After-hours Power Status, by Building Type

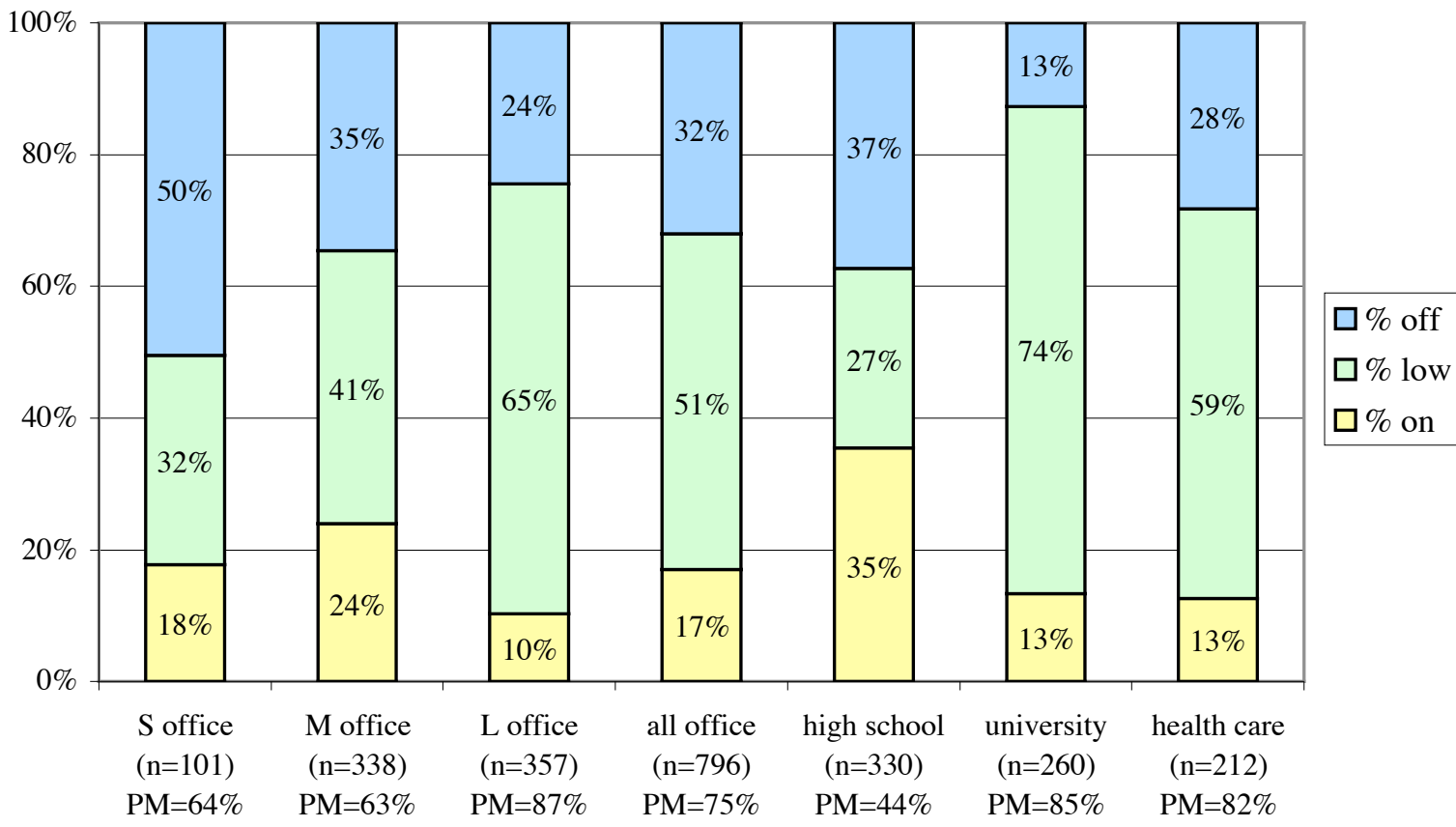

In our sample, monitor PM rates were by far the lowest in high schools (44\%) and highest in university buildings (85\%) and large offices (87\%). Monitor turn-off rates were lowest in university buildings (13\%) and highest in small offices (50\%). In addition to the low monitor PM rate, a relatively high number (35\%) of monitors were on in high schools, where all monitors found were CRTs, which use significantly more power when on than LCDs (Roberson, 2002). This strengthens the evidence that there is significant energy savings potential among office equipment in computer classrooms, and particularly those in high schools. 


\section{Printers}

We categorize printers based on imaging technology: laser, inkjet, impact, thermal, wide format, solid ink. ${ }^{4}$ Figure 5 shows the composition of our sample. Of 385 printers, $45 \%$ (174) were laser, $34 \%$ (132) were inkjet, $11 \%$ (41) were thermal, $6 \%$ (25) were impact, $2 \%$ (8) were wide format, and $1 \%$ (4) were solid ink.

\section{Figure 5. Printer Sample, by Technology}

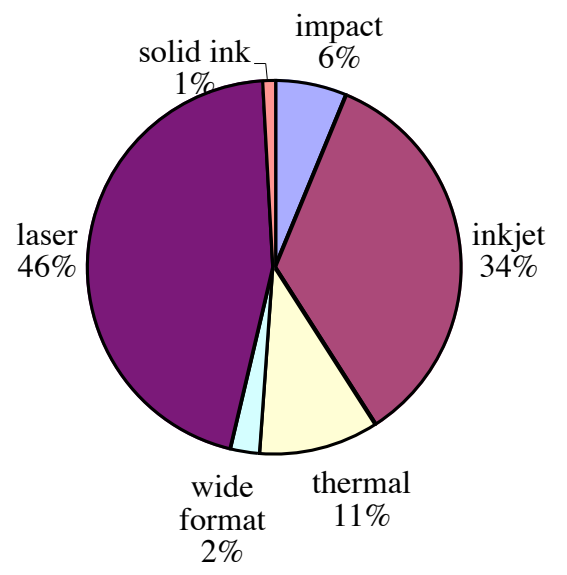

Of 158 laser printers in our sample, $15 \%$ were off, and $60 \%$ of those not off were in low power mode. Among the 123 inkjet printers the turn-off rate was $30 \%$; we found no inkjet printers in low power. Of 38 thermal printers, which do not power manage, the turn-off rate was $18 \%$. Of four solid ink printers none were off, but three $(75 \%)$ were in low power.

For laser printers we tried to record "powersave" (i.e., low power) delay settings and whether or not they were networked. We did not record delay settings for laser printers that were off, or for those that did not have user interactive menus. Of 78 laser printers for which we actually recorded delay settings, $18 \%$ (14) were set to 15 minutes, $59 \%$ (46) were 30 minutes, $12 \%$ (9) were 60 minutes, 6\% (5) were 180-240 minutes, and $5 \%$ (4) were set to "never" or off. Figure 6 displays this graphically.

Figure 6. Laser Printers: Powersave Delay Settings

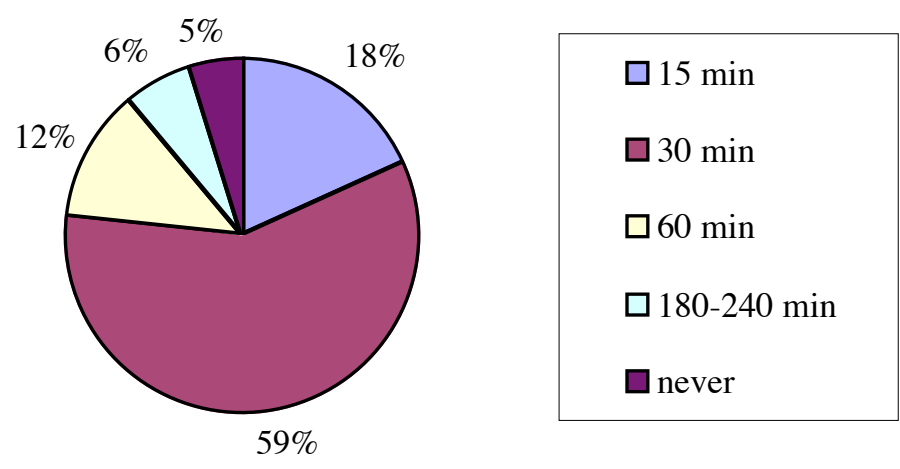

\footnotetext{
${ }^{4}$ Wide-format is not an imaging technology, but rather an ENERGY STAR category for printers that accommodate 17" $\mathrm{x}$ 22 " or larger paper. Of 8 wide format printers in our sample, 7 used inkjet, and one used impact technology.
} 
Among printers for which we recorded the presence or absence of a network connection, $63 \%$ of laser printers but only $7 \%$ of inkjet printers were networked.

Only $60 \%$ of laser printers not off were actually found in low power (see Table 3). Not all laser printers can power manage (i.e., they are not ENERGY STAR), and so do not have powersave delay settings. Among laser printers that can power manage, there are several reasons they might be found on during our survey: (1) the printer has a long (3-4 hour) powersave delay setting, which had not elapsed, (2) the printer was recently used, and (3) the printer is in error mode, which effectively prevents it from entering low power.

\section{Multi-Function Devices}

The ENERGY STAR Office Equipment program distinguishes 'digital copier-based MFDs,' which are covered by their MFD program, from printer- and fax-based MFDs, which are covered by their printer program. In this study, we identify any multi-function device as an MFD, and distinguish between them on the basis of imaging technology (inkjet or laser), which we think is most relevant to power consumption.

Many units of office equipment that we identified in the field as copiers, fax machines, or printers turned out, on later examination of their specifications, to actually be multi-function devices. Among the 80 MFDs eventually identified, $80 \%$ (64) used laser technology, and the remaining 20\% (16) were inkjets. Turn-off and PM rates were similar for laser and inkjet MFDs. Of 63 laser MFDs in Table 3 the turn-off rate was $21 \%$, and $28 \%$ of those that were not off were in low power. Of 16 inkjet MFDs (at least some of which can power manage) the turn-off rate was $19 \%$, and $31 \%$ of those not off were in low power.

\section{Copiers}

Of the 33 copy machines in Table 3, 48\% were off and $29 \%$ of those that were not off were in low power. This low PM rate may be due in part to the fact that copiers often have powersave delay settings of two hours or more, and some of the copiers that we found on would eventually have entered low power.

Our 2000 field surveys of office equipment included 34 copiers and 11 'digital copier-based MFDs,' which yields a copier to 'digital copier-based MFD' ratio of 3:1. Our current sample includes 33 copiers and 64 laser or 'digital copier-based MFDs,' which yields a 2003 copier to 'digital copier-based MFD' ratio of 0.5:1. These numbers confirm our field observations that MFDs are replacing copiers in the marketplace.

\section{Fax Machines}

It can be difficult to tell whether a fax machine is on or in low power. Also, many units meet ENERGY STAR's low power requirement when on but idle or 'ready', and so do not need a separate low power mode. In this study, unless a fax machine gave a visual indication that it was in low power, we recorded it as being on. Of the 47 units in our sample and in Table 3 , none were off and 6\% (3) were in low power. Of the 44 fax machines whose technology we were able to determine, 69\% (30) were laser, 20\% (9) were thermal, and $11 \%(5)$ were inkjet. Figure 7 displays this graphically.
Figure 7. Fax Machine Technology

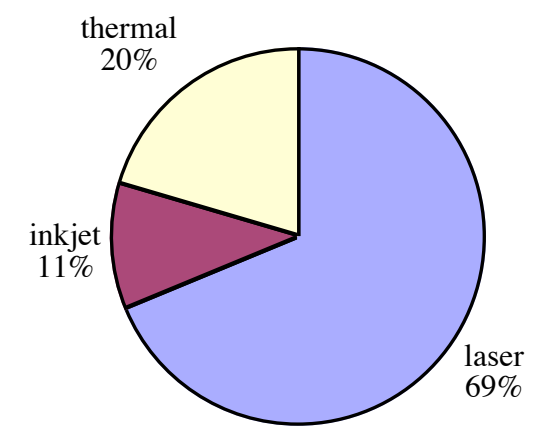




\section{Scanners}

Of the 34 scanners in Table 3, $41 \%$ were off and $60 \%$ of those that were not off were in low power. Of the total 37 scanners in our sample, 76\% (28) were flatbed scanners, 14\% (5) were specialized document scanners, $5 \%$ (2) were wide format, and 5\% (2) were slide scanners. Among flatbed scanners only, $18 \%$ (5) were on, $43 \%$ (18) were in low power, $29 \%$ (8) were off, and $11 \%$ (3) were unplugged. All five document scanners were off; both wide format scanners were found in the same room, and were on.

\section{Office Equipment: Comparison of 2000 and 2003 Turn-off and PM Rates}

A primary goal of this study is to update information on office equipment turn-off and power management rates from previous studies, and to broaden the range of buildings in which this data is collected. Table 7 compares the office equipment turn-off and PM rates from this series of surveys to those from our 2000 field surveys of office buildings in California (Webber, Roberson et al. 2001).

In most cases, our 2003 field data yield turn off and PM rates that are virtually the same as those found in 2000. Notable exceptions are that monitor PM rates were higher ( $72 \%$ in 2003 c.f. $56 \%$ in 2000) and MFD PM rates were much lower in 2003 than in 2000 (29\% in 2003 c.f. 56\% in 2000). Also, copier and scanner turn-off rates were higher in 2003 than in 2000.

Table 7. Office Equipment Turn-off and Power Management Rates

\begin{tabular}{|c|c|c|c|c|c|c|}
\hline & \multirow[b]{2}{*}{ Type } & \multirow[b]{2}{*}{ no. in 2003} & \multicolumn{2}{|c|}{ Turn-off Rate } & \multicolumn{2}{|c|}{ PM Rate } \\
\hline Category & & & 2000 & 2003 & 2000 & 2003 \\
\hline \multirow[t]{3}{*}{ computers } & desktop + ICS & 1,498 & $44 \%$ & $37 \%$ & $5 \%$ & $7 \%$ \\
\hline & desktop & 1,453 & & $36 \%$ & & $6 \%$ \\
\hline & ICS & 45 & & $60 \%$ & & $61 \%$ \\
\hline \multirow[t]{3}{*}{ monitors } & all & 1,598 & $32 \%$ & $29 \%$ & $56 \%$ & $72 \%$ \\
\hline & CRT & 1,329 & & $32 \%$ & & $71 \%$ \\
\hline & LCD & 269 & & $18 \%$ & & $75 \%$ \\
\hline \multirow[t]{9}{*}{ printers } & all & 353 & $25 \%$ & $23 \%$ & $44 \%$ & $31 \%$ \\
\hline & monochrome laser & & $24 \%$ & & $53 \%$ & \\
\hline & high-end color & & $15 \%$ & & $61 \%$ & \\
\hline & laser & 158 & & $15 \%$ & & $60 \%$ \\
\hline & inkjet & 123 & $31 \%$ & $30 \%$ & $3 \%$ & $\mathbf{0 \%}$ \\
\hline & impact & 22 & $31 \%$ & $27 \%$ & $0 \%$ & $0 \%$ \\
\hline & thermal & 38 & & $18 \%$ & & $0 \%$ \\
\hline & wide format & 8 & $57 \%$ & $75 \%$ & $32 \%$ & $0 \%$ \\
\hline & solid ink & 4 & & $0 \%$ & & $75 \%$ \\
\hline \multirow[t]{3}{*}{ MFDs } & all & 79 & $18 \%$ & $20 \%$ & $56 \%$ & $29 \%$ \\
\hline & inkjet & 16 & & $19 \%$ & & $31 \%$ \\
\hline & laser & 63 & & $21 \%$ & & $28 \%$ \\
\hline copiers & all & 33 & $18 \%$ & $49 \%$ & $32 \%$ & $28 \%$ \\
\hline fax machines & all & 47 & $2 \%$ & $0 \%$ & & $6 \%$ \\
\hline scanners & all & 34 & $29 \%$ & $41 \%$ & & $60 \%$ \\
\hline
\end{tabular}

For computers, the $2003 \mathrm{PM}$ rate of $6 \%$ is similar to the estimated 2000 rate of $5 \%$, but the 2003 turn-off rate of $36 \%$ for desktop computers is lower than the 2000 turn-off rate of $44 \%$ for all computers. 
The 2003 turn-off rate of $32 \%$ for CRTs matches the 2000 turn-off rate for all monitors, but the 2003 turnoff rate of $18 \%$ for LCD monitors is much lower. In 2003 we found a much higher PM rate for both CRT and LCD monitors (71\% and 75\%, respectively) than the 56\% PM rate reported for all monitors in 2000.

For all laser printers (of which $<2 \%$ are color) our 2003 turn-off rate of $15 \%$ is lower than the 2000 rate of $24 \%$ for monochrome laser printers. The 2003 turn-off rates for inkjet (30\%) and impact (27\%) printers are similar to the 2000 rates for both (31\%). Among our small sample of 8 wide format printers in 2003, the $75 \%$ turn-off rate is significantly higher than the 57\% reported in 2000 . The 2003 turn-off rate of $0 \%$ for (a sample of four) solid ink printers is lower than the 2000 turn-off rate of $15 \%$ for high-end color printers.

The 2003 PM rate of $60 \%$ for laser printers is similar to the 2000 rate of $61 \%$ for "high end color" printers. In 2000 some inkjet and wide-format printers were in low power, but in 2003 we found none.

The 2000 study did not report on thermal or solid ink printers, probably because few or none were found. Solid ink is not a widespread printer technology; in 2003 we found four, all in the same building. Of 41 thermal printers in our 2003 sample, only 15\% were found in offices; another 15\% were in education buildings, but $70 \%$ were found in health care buildings. For thermal printers the 2003 turn-off rate is $18 \%$; for solid ink printers it is $0 \%$. The $2003 \mathrm{PM}$ rate for thermal printers is $0 \%$; for solid ink it's $75 \%$.

In 2003 we distinguish between laser and inkjet MFDs, but their turn-off rates (19 and 21\%, respectively) are similar to the 2000 rate of $18 \%$ for all MFDs. However, in 2003 the PM rate for both inkjet and laser MFDs (31 and 28\%, respectively) are significantly lower than the 2000 rate of $56 \%$ for all MFDs.

Copiers had a much higher turn-off rate in 2003 (49\%) than in 2000 (18\%), but their PM rate in 2003 $(28 \%)$ is slightly lower than in $2000(32 \%)$. Because of confusion about fax machine power state, no PM rate was reported in 2000; however, in 2003, at least $6 \%$ of fax machines were in low power. For scanners, the turn-off rate rose from $29 \%$ in 2000 to $41 \%$ in 2003; the 2003 PM rate was $60 \%$.

\section{Miscellaneous Equipment}

\section{Miscellaneous Equipment: Numbers and Density}

Miscellaneous equipment outnumbered office equipment in all buildings except one (a university, site A); at one medium office (site E), the ratio of miscellaneous equipment to office equipment exceeded 4:1. For all buildings combined, if external power supplies are included as miscellaneous equipment, the ratio of miscellaneous equipment units (7,668, Appendix D) to office equipment $(3,934$, Table 2$)$ is almost 2:1.

For all buildings combined, the most numerous equipment types in each ME category are as follows:

- audio/visual: television (27\% of audio/visual category), VCR (23\%), overhead projector (14\%)

- food/beverage: microwave oven (16\%), undercabinet refrigerator (15\%), coffee maker (12\%)

- $\quad$ portable hvac: $8-16$ " diameter fan $(35 \%)$, heater $(21 \%),<8$ " diameter fan $(20 \%)$

- laboratory: scale (24\%), spectrophotometer (18\%), tabletop centrifuge (13\%)

- lighting:

- medical:

- networking:

- office misc.:

- peripheral:

- power:

- telephony:

- maintenance: fluorescent undercabinet lamp (60\%), 13W compact fluorescent lamp (15\%) oto-opthalmoscope charger (25\%), exam light (18\%), x-ray light box (12\%) switch (30\%), hub (22\%), modem (14\%) clock and/or radio (22\%), compact audio system (18\%), pencil sharpener (17\%) computer speaker pair (52\%), laptop docking station (12\%), PDA dock (11\%) lighted power strip (36\%), plug-in power supply (35\%), in-line power supply (8\%) powered phone (42\%), headset with network box (13\%), conference phone (11\%) vacuum cleaner $(21 \%)$, floor polisher (14\%), clothes washer or dryer $(12 \%)$. 
Appendix D lists the number of miscellaneous equipment units, by category, found in each building. For all sites combined, the most numerous miscellaneous equipment categories are power (including external power supplies, which are discussed in the following section), lighting, and computer peripherals. The least numerous categories of plug-load miscellaneous equipment are money exchange and security. Figure $\underline{8}$ shows the relative numbers of each category of miscellaneous equipment, by type of building, and Figure $\underline{9}$ shows the density of each equipment category, in number of units per $1000 \mathrm{ft}^{2}$ of floor area surveyed.

Figure 8. Miscellaneous Equipment Numbers, by Category and Building Type

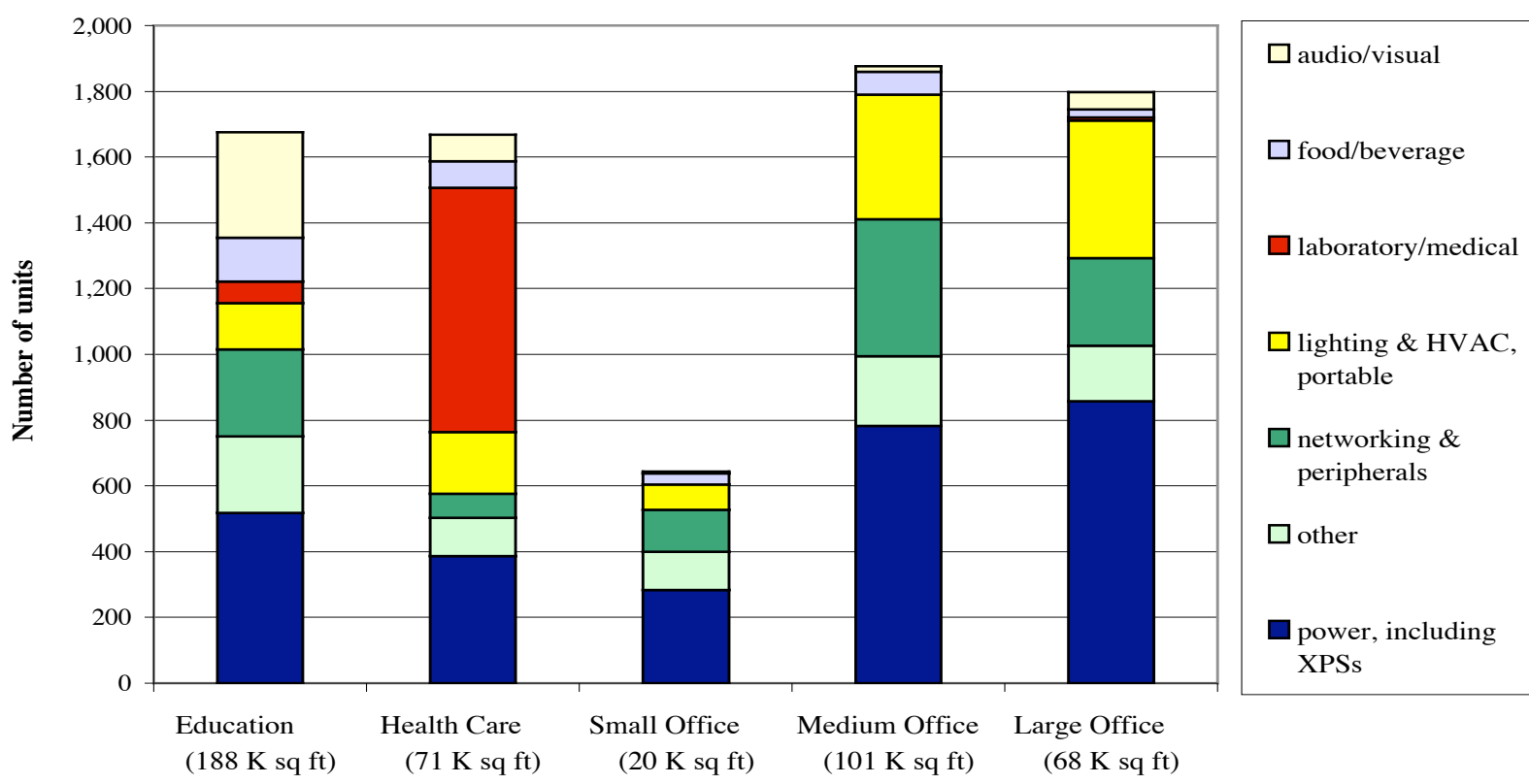

Figure 9. Miscellaneous Equipment Density, per $1000 \mathrm{ft}^{2}$ Floor Area

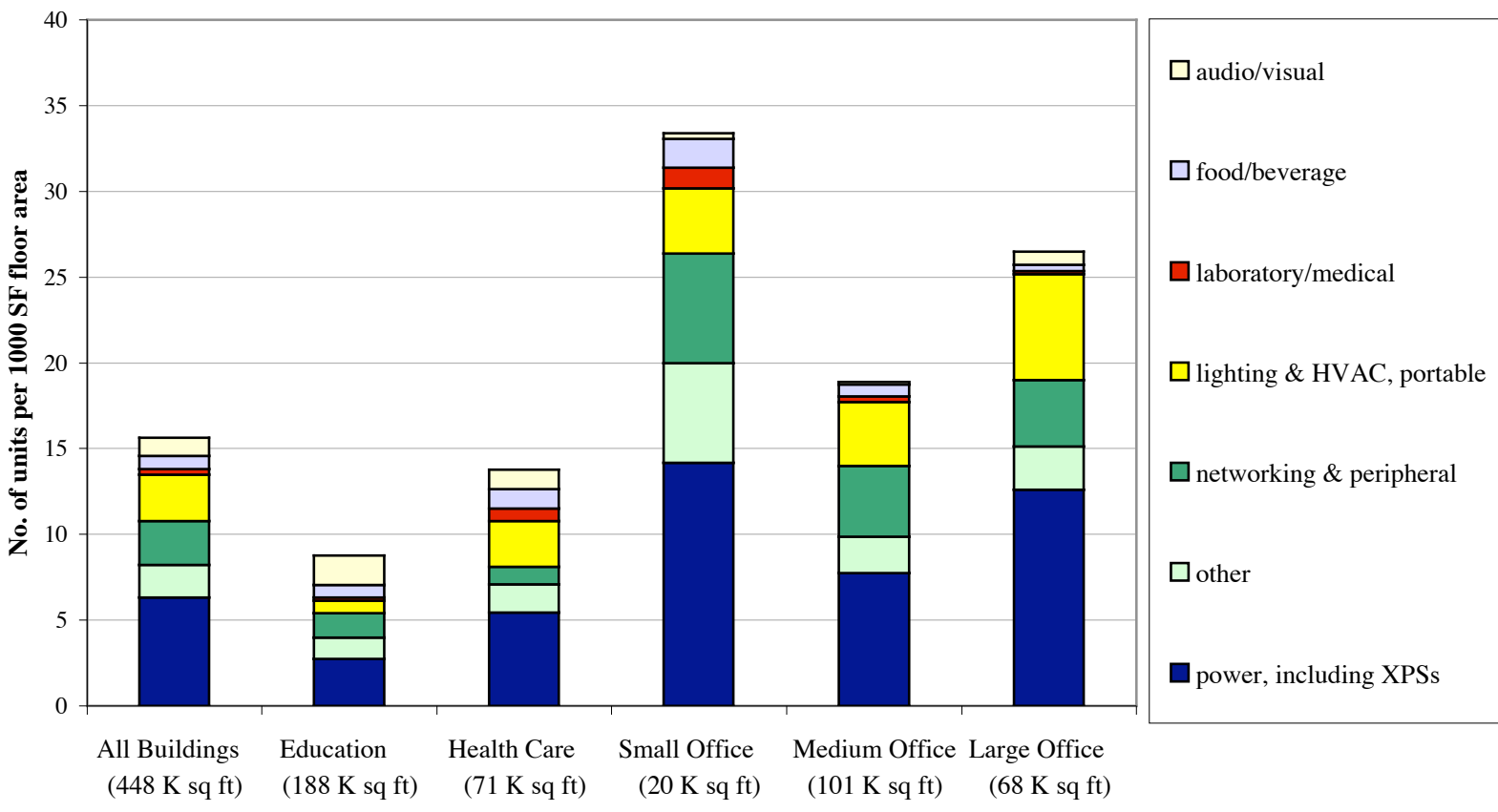


In Figures 8-11, some miscellaneous equipment categories have been combined for easier comparison. Specifically, we combined laboratory with medical and medical specialty, portable lighting with portable HVAC, and networking equipment with computer peripherals; 'other' combines the categories of money exchange, office miscellany, security, telephony, and utility/maintenance.

Not surprisingly, laboratory and medical equipment is the largest miscellaneous equipment category (in terms of number of units) in health care buildings, and audio/visual equipment is a significant category in education buildings. Networking equipment appears to be a smaller category in large offices; however, this result may be because we did not have access to network closets in the two large offices in our sample.

\section{Miscellaneous Equipment: Relative Energy Consumption}

An inventory is a necessary starting point, but does not reveal the relative total energy consumption (TEC) of ME found in our survey. For that we must first estimate the typical UEC of each type of equipment, which, when multiplied by number of units found, yields an estimate of TEC. We were able to estimate the UEC and TEC for over $70 \%$ ( 230 of 321 types) of ME found among buildings in this survey.

Typical unit energy consumption is the sum of the products of the power consumed in each power state (unplugged, off, on, active) and the likely number of hours per year (or percent time) spent in each state. We used data from previous metering projects and other available sources to estimate both parameters. In some cases we found UEC estimates in the literature. To estimate power consumed in each power state, we relied primarily on metering data by LBNL and others, online and published sources, and comparison to similar devices for which we have data (AD Little 1996, Cadmus 2000, USDOE 1995, Wenzel 1997).

In all cases, for both power levels and usage patterns, we recorded the basis of our estimates in order to facilitate subsequent evaluation and revision of our estimates based on new information or assumptions. To estimate the portion of time each type of miscellaneous equipment typically spends in each power state, we used data on as-found power states collected in this survey, supplemented by educated guesswork and personal experience. Here are some examples:

- we assumed that refrigerators, freezers, and refrigerated vending machines are always on,

- we estimated that microwave ovens in office lunchrooms are used 5 hours/week on average,

- $80 \%$ of VCRs found were on; we assume they are always on and estimated additional $10 \%$ usage,

- $60 \%$ of over 450 computer speaker pairs in our survey were found on; we used that data without adjustment, assuming that speakers found off during our survey were virtually always off.

Of course, for each type of equipment, usage and UEC may vary depending on the setting in which it is found. For example, a TV in a high school classroom is likely to be used less often that it would in a home. Similarly, a coffee maker is likely to be used more often in a typical office than it would in a typical home. Our UEC estimates apply to the buildings that we surveyed and do not necessarily apply in other situations.

We prioritized the considerable effort of estimating UECs by focusing on the most numerous and most energy-intensive equipment types. Miscellaneous equipment for which we do not have UEC (and therefore TEC) estimates include some specialized medical equipment and other equipment we could not meter and for which we could find no power specifications. That we do not have estimates of power use for some equipment does not mean that their consumption is insignificant, only that we were unable to estimate it at this time. Examples of equipment for which we have no estimate (with the number of them found) are:

- audio/visual category: video switch (9), power distribution \& lighting system (5),

- food \& beverage category: hot beverage dispenser (4), steam trays (3),

- peripheral category: keyboard/video/mouse (KVM) switch (27), pen tablet (17)

- power category: battery backup system (3), power amplifier (2) 
For the 230 types of miscellaneous equipment for which we have estimates of both power consumption and time spent in each power mode, it is a simple matter to calculate typical unit energy consumption and (multiplying UEC by the number of units found) to calculate their total energy consumption. Obviously, any error in the UEC estimate is compounded (multiplied) by the number of units found. Also, the more power consumed and the more time spent on, the larger the potential error in our (absolute kWh) estimates.

Our UEC estimates ranged from $1 \mathrm{kWh} / \mathrm{yr}$ for pencil sharpeners to 7,008 $\mathrm{kWh} / \mathrm{yr}$ for kilns; TEC estimates ranged from $1 \mathrm{kWh} / \mathrm{yr}$ (e.g., for one shaver) to almost 80,000 kWh/yr for 24 refrigerated vending machines.

Networking equipment in our survey, primarily ethernet hubs and switches, ranged from 1 to 80 ports each. Our inventory distinguishes these equipment by the number of ports (e.g., we list the number of 12-, 16-, 24-, 48-, and 80-port hubs separately), but our estimates of UEC and TEC are based on the sum of all ports, regardless of unit configuration. We found a total 2,120 ethernet switch ports and 451 ethernet hub ports.

Of the miscellaneous equipment for which we have UEC and TEC estimates, Table 8 shows the total energy consumption of miscellaneous equipment according to our categories. The top 50 in unit energy consumption are listed in Table 9 and the top 50 in total energy consumption are listed in Table 10.

The food \& beverage category appears to dominate miscellaneous equipment in terms of unit energy consumption; eleven of the top 15 equipment types in terms of UEC are in the food \& beverage category, which are shaded in Tables 9 and 10. The food \& beverage category also dominates in terms of total energy consumption, accounting for half $(50 \%)$ of total energy consumed. Table 10 shows that among our survey of commercial buildings the top ten types of food $\&$ beverage equipment in terms of TEC are:

1) refrigerated vending machines 6) hot food cabinets

2) commercial refrigerators 17$)$ coffee makers, residential models

3) commercial freezers 8) small (undercabinet) refrigerators

4) microwave ovens 9) room temperature vending machines

5) coffee makers, commercial or specialty $\quad$ 10) visi-coolers

While each ethernet switch port has a UEC of just $17 \mathrm{kWh} / \mathrm{yr}$, the over 2,000 units have a collective TEC of over 35,000 kWh/year, which suggests this equipment is a good target for energy efficiency measures. We estimate that computer speaker pairs collectively account for almost 10,000 kWh/yr in these buildings; because these units are seldom used, their consumption represents a considerable energy savings potential.

Table 8. Total Energy Consumption of Miscellaneous Equipment, by Category

$\begin{array}{rrr}\text { Miscellaneous Equipment Category } & \text { TEC }(\mathbf{k W h} / \mathbf{y r}) & \mathbf{\%} \text { of Sum } \\ \text { food/beverage } & 354,406 & 50 \% \\ \text { laboratory/medical } & 72,583 & 10 \% \\ \text { networking } & 53,775 & 8 \% \\ \text { audio/visual } & 43,036 & 6 \% \\ \text { lighting, portable } & 42,417 & 6 \% \\ \text { computer peripherals } & 35,549 & 5 \% \\ \text { other (money exchange, security, specialty, utility/maintenance) } & 38,285 & 5 \% \\ \text { hvac, portable } & 26,731 & 4 \% \\ \text { power, including XPSs } & 26,079 & 4 \% \\ \text { office miscellany } & 13,114 & 2 \% \\ \text { telephony } & 7,616 & 1 \% \\ \text { All Miscellaneous Equipment Found in Survey } & \mathbf{7 1 3 , 5 9 1} & \mathbf{1 0 0 \%}\end{array}$


Figure 10. TEC of Miscellaneous Equipment, Normalized by Floor Area (kWh/yr per $\left.1000 \mathrm{ft}^{2}\right)$

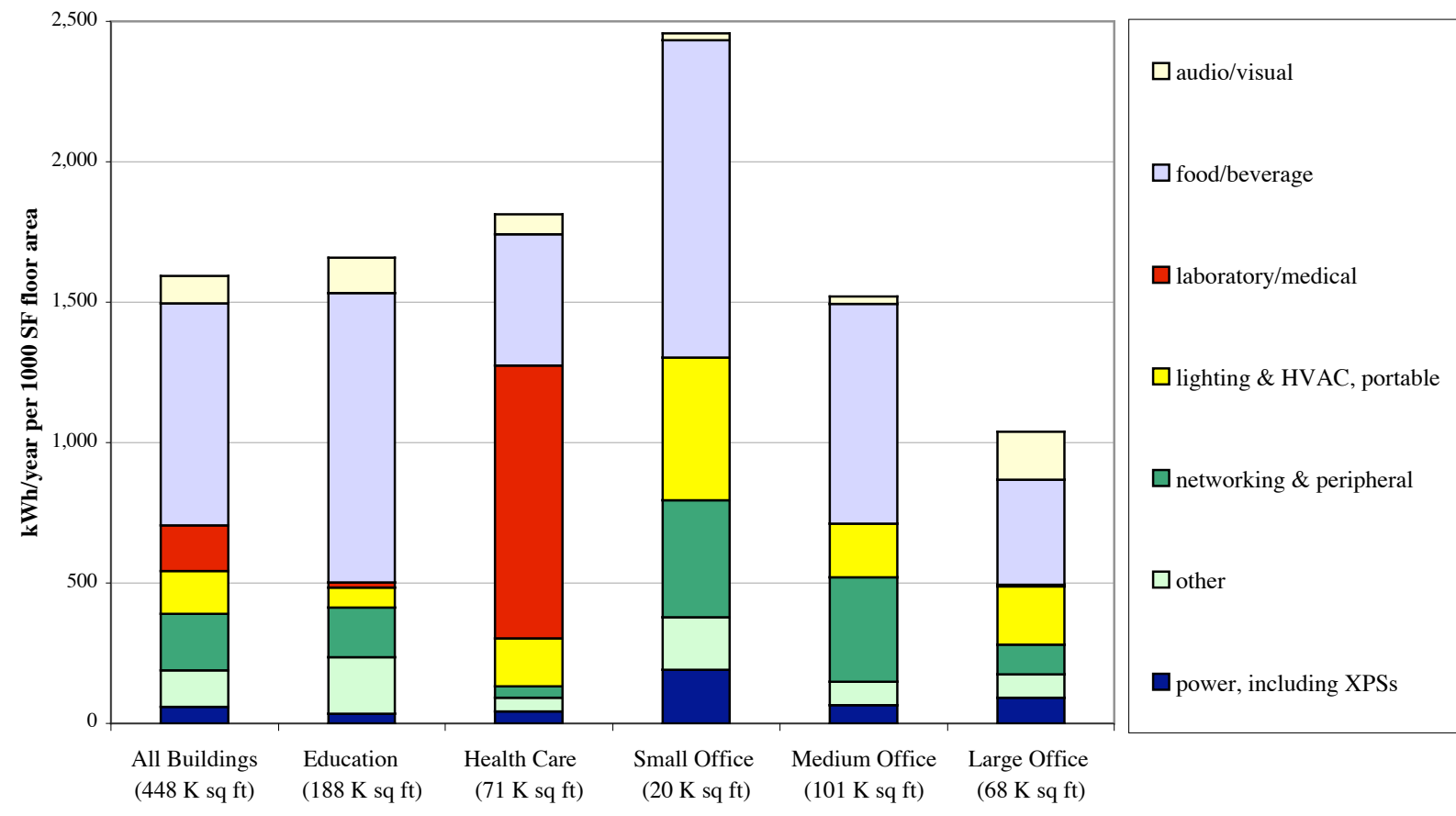

Figures 8-10 show that although small offices have the lowest numbers of miscellaneous equipment, they have the highest density, in both numbers and TEC, in all categories except audio/visual. This is consistent with Figure 2, in which small offices have the highest density of both office and miscellaneous equipment.

Figure 11. TEC of Miscellaneous Equipment, as Percent of Building Type

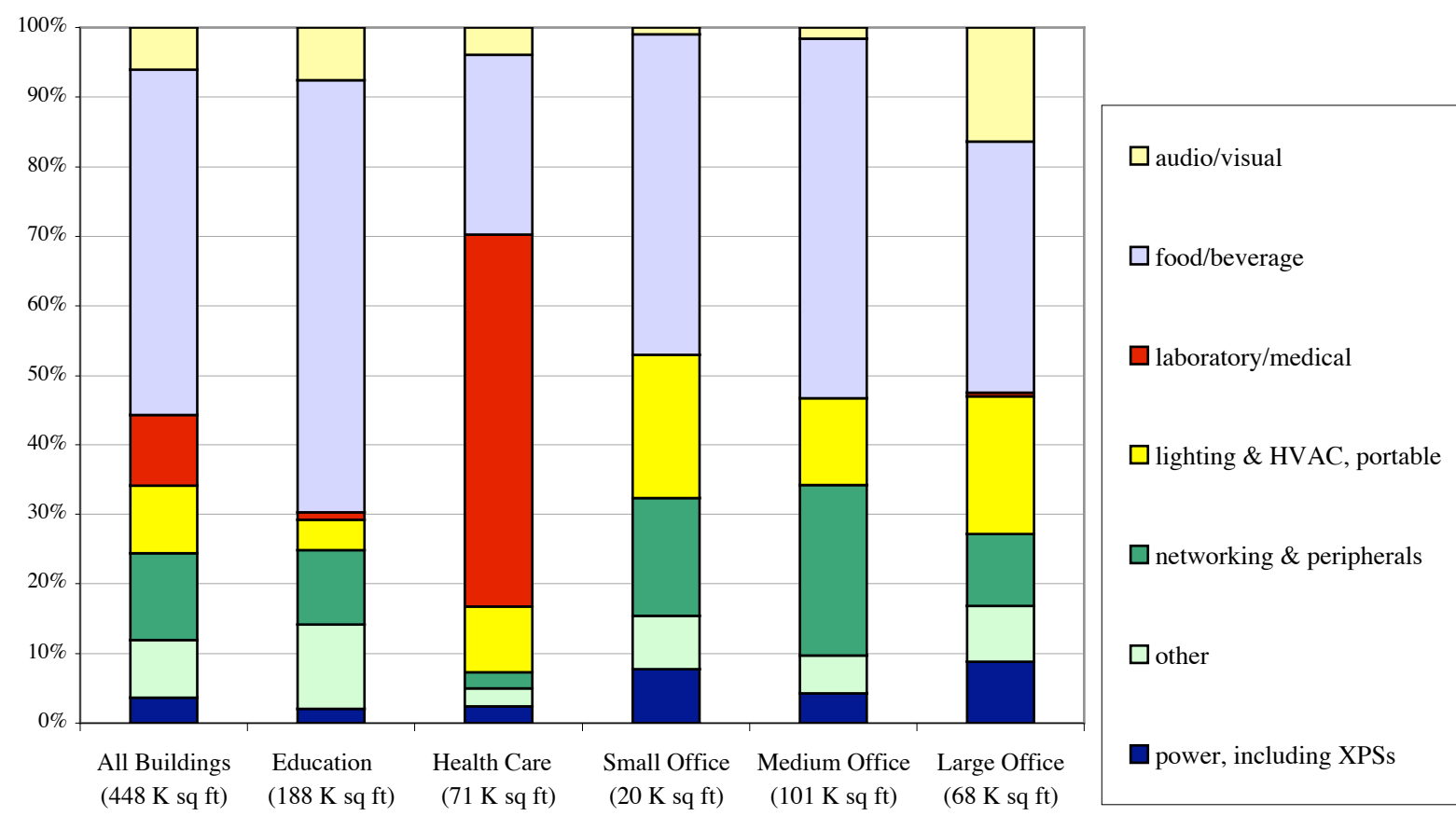


Table 9. Top 50 Miscellaneous Equipment Types, by Unit Energy Consumption

Note: Shading indicates equipment in the food \& beverage category

Note: * indicates equipment for which we found and used published UEC values.

\begin{tabular}{|c|c|c|c|c|c|c|c|c|}
\hline \multirow[b]{3}{*}{1} & \multicolumn{2}{|c|}{ Miscellaneous Equipment } & \multicolumn{2}{|c|}{ Power Use (W) } & \multicolumn{3}{|c|}{ Estimated Usage (percent time) } & \multirow{2}{*}{$\begin{array}{c}\text { Unit Energy } \\
\text { Consumption } \\
\text { (UEC) kWh/yr }\end{array}$} \\
\hline & Category & Type & On & Off & On & Off & Unplugged & \\
\hline & specialty & kiln & 8000 & & $10 \%$ & $0 \%$ & $90 \%$ & 7,008 \\
\hline 2 & food \& beverage & fryer & & & & & & * 5,884 \\
\hline 3 & food \& beverage & freezer, commercial & & & & & & $* 5,200$ \\
\hline 4 & food \& beverage & hot food cabinet & & & & & & $* 4,700$ \\
\hline 5 & food \& beverage & refrigerator, commercial & & & & & & $* 4,300$ \\
\hline 6 & laboratory & autoclave & 1500 & 0 & $30 \%$ & $50 \%$ & $20 \%$ & 3,942 \\
\hline 7 & food \& beverage & visi-cooler & & & & & & $* 3,900$ \\
\hline 8 & food \& beverage & vending machine, cold beverage & & & & & & $* 3,318$ \\
\hline 9 & food \& beverage & ice maker & & & & & & $* 2,167$ \\
\hline 10 & food \& beverage & vending machine, room $\mathrm{T}$ snack & 205 & & $100 \%$ & $0 \%$ & $0 \%$ & 1,796 \\
\hline 11 & food \& beverage & coffee maker, commercial or specialty & 2595 & & $6 \%$ & $74 \%$ & $20 \%$ & 1,349 \\
\hline 12 & laboratory & drying oven or steam incubator & 300 & 0 & $50 \%$ & $50 \%$ & $0 \%$ & 1,314 \\
\hline 13 & food \& beverage & refrigerated case & & & & & & $* 1,214$ \\
\hline 14 & audio/visual & LED display sign, networked & 135 & 15 & $100 \%$ & $0 \%$ & $0 \%$ & 1,183 \\
\hline 15 & food \& beverage & soda fountain pump or smoothie maker & 100 & 0 & $100 \%$ & $0 \%$ & $0 \%$ & 876 \\
\hline 16 & networking & switch, fiberoptic, 24 port & 96 & & $100 \%$ & $0 \%$ & $0 \%$ & 841 \\
\hline 17 & food \& beverage & bottled water tap, hot \& cold & & & & & & $* 799$ \\
\hline 18 & food \& beverage & water cooler, hot \& cold & & & & & & $* 799$ \\
\hline 19 & HVAC, portable & air cleaner & & & & & & $* 761$ \\
\hline 20 & utility/maintenance & clothes washer & & & & & & $* 704$ \\
\hline 21 & food \& beverage & refrigerator, L (full-size) & & & & & & $* 701$ \\
\hline 22 & food \& beverage & refrigerator/freezer & & & & & & $* 701$ \\
\hline 23 & peripheral & external drive, tape backup & 100 & & $80 \%$ & $10 \%$ & $10 \%$ & 701 \\
\hline 24 & audio/visual & system control, rack-mount & 79 & 5 & $100 \%$ & $0 \%$ & $0 \%$ & 692 \\
\hline 25 & audio/visual & power/volume controller & 79 & 5 & $100 \%$ & $0 \%$ & $0 \%$ & 692 \\
\hline 26 & HVAC, portable & room air conditioner & & & & & & $* 630$ \\
\hline 27 & utility/maintenance & clothes dryer & & & & & & $* 622$ \\
\hline 28 & specialty & bookshelves, mobile & 70 & 0 & $100 \%$ & $0 \%$ & $0 \%$ & 613 \\
\hline 29 & utility/maintenance & pump, water treatment chemical & 70 & 0 & $100 \%$ & $0 \%$ & $0 \%$ & 613 \\
\hline 30 & food \& beverage & refrigerator, $\mathbf{M}$ (apt-size) & & & & & & $* 567$ \\
\hline 31 & utility/maintenance & exhaust fan, industrial & 125 & 0 & $50 \%$ & $50 \%$ & $0 \%$ & 548 \\
\hline 32 & laboratory & refrigerator, $\mathrm{S}$ & 60 & 0 & $100 \%$ & $0 \%$ & $0 \%$ & 526 \\
\hline 33 & laboratory & freezer & 60 & 0 & $100 \%$ & $0 \%$ & $0 \%$ & 526 \\
\hline 34 & lighting, portable & incandescent tracklight, 50 lamps each & 2000 & 0 & $3 \%$ & $97 \%$ & $0 \%$ & 520 \\
\hline 35 & telephony & phone/PBX centrex system & 55.5 & & $100 \%$ & $0 \%$ & $0 \%$ & 486 \\
\hline 36 & food \& beverage & coffee maker, residential model & 865 & 0 & $6 \%$ & $69 \%$ & $25 \%$ & 450 \\
\hline 37 & food \& beverage & microwave oven & 1620 & 3 & $3 \%$ & $97 \%$ & $0 \%$ & 447 \\
\hline 38 & medical specialty & charger, suction pump & 50 & 3 & $100 \%$ & $0 \%$ & $0 \%$ & 438 \\
\hline 39 & peripheral & disk array & 50 & & $100 \%$ & $0 \%$ & $0 \%$ & 438 \\
\hline 40 & networking & tape drive & 100 & & $50 \%$ & $50 \%$ & $0 \%$ & 438 \\
\hline 41 & medical specialty & sterilizer, hot bead & 90 & & $50 \%$ & $50 \%$ & $0 \%$ & 394 \\
\hline 42 & audio/visual & digital video camera & 70 & 3 & $60 \%$ & $40 \%$ & $0 \%$ & 378 \\
\hline 43 & networking & router & 40 & & $100 \%$ & $0 \%$ & $0 \%$ & 350 \\
\hline 44 & peripheral & external drive, other & 50 & & $80 \%$ & $20 \%$ & $0 \%$ & 350 \\
\hline 45 & medical specialty & charger, defibrillator & 50 & 3 & $75 \%$ & $25 \%$ & $0 \%$ & 335 \\
\hline 46 & HVAC, portable & heater & 750 & & $5 \%$ & $48 \%$ & $48 \%$ & 329 \\
\hline 47 & peripheral & external drive, hard disk & 50 & & $67 \%$ & $25 \%$ & $8 \%$ & 292 \\
\hline 48 & food \& beverage & refrigerator, $\mathrm{S}$ (undercabinet) & & & & & & * 277 \\
\hline 49 & networking & video processor, rack-mount & 30 & & $100 \%$ & $0 \%$ & $0 \%$ & 263 \\
\hline 50 & lighting, portable & incandescent studio lamp, $500 \mathrm{~W}$ & 500 & 0 & $6 \%$ & $94 \%$ & $0 \%$ & 260 \\
\hline
\end{tabular}

Finally, we characterized the top 50 miscellaneous equipment types in Table 10 according to these broader end-use or technology categories: electronics, heating, lighting, motors, and refrigeration. For equipment that could belong in more than one of these categories, we categorized it based on its primary technology or consumption. For example, refrigerated vending machines are a 'refrigeration' end use, while room temperature vending machines are 'lighting;' microwave ovens and computer projectors are categorized as 'electronics' although they might alternatively be categorized as 'heating' and 'lighting,' respectively. Figure 12 shows the relative consumption of equipment in Table 10 according to these end-use categories. 
Table 10. Top 50 Miscellaneous Equipment Types, by Total Energy Consumption

Note: Shading indicates equipment in the food \& beverage category

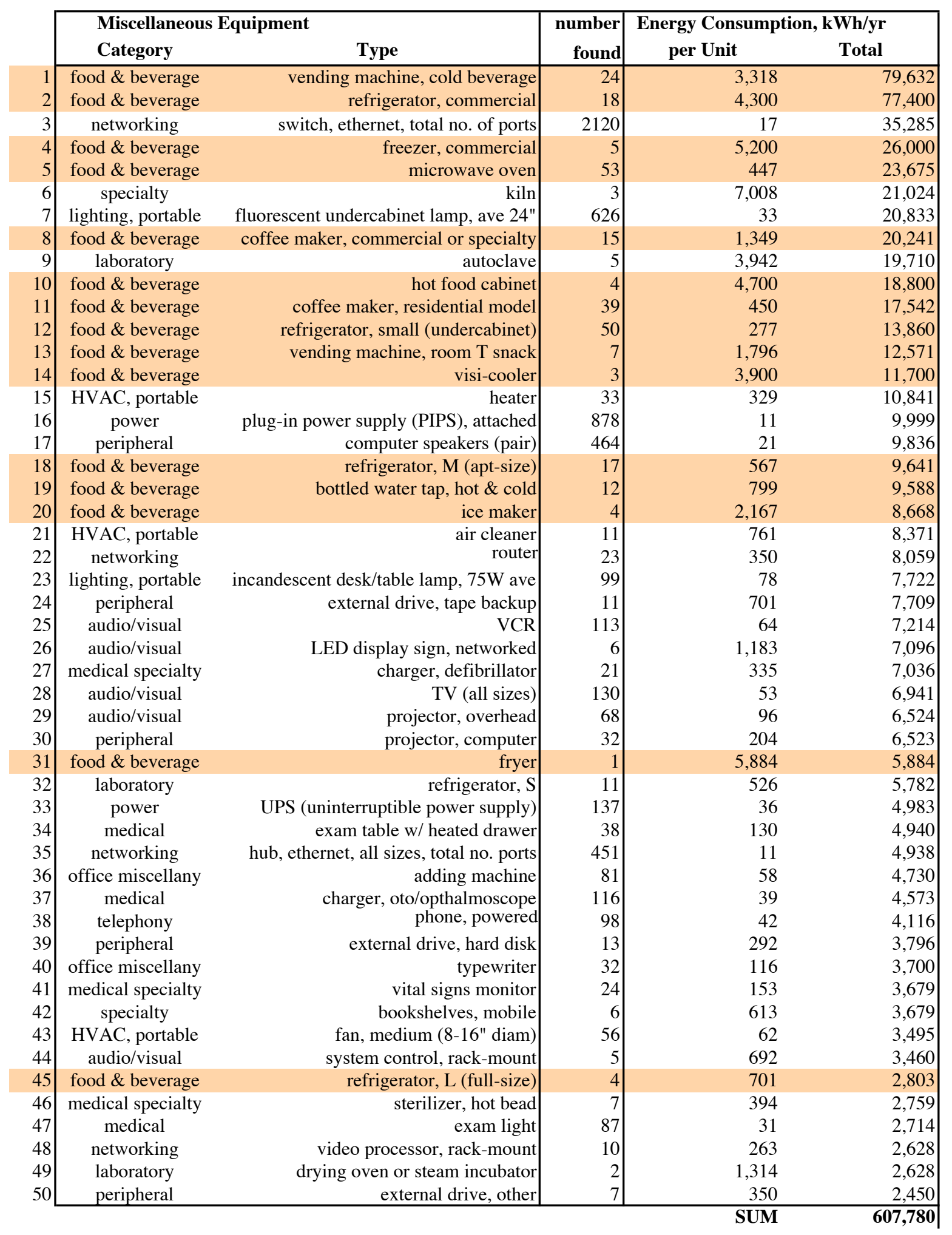


Figure 12. End-Use Breakdown of Top 50 Miscellaneous Equipment Types, by TEC

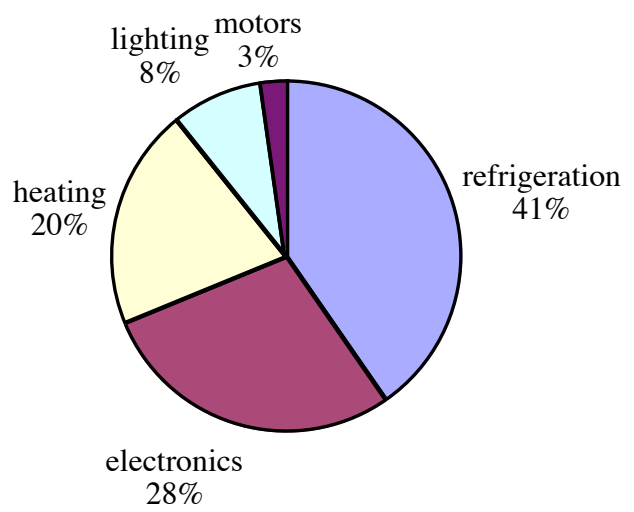

\section{External Power Supplies}

Figure 13 shows the types of equipment we found with external power supplies, the number of units of each equipment type that had an XPS, the type of power supply (ILPS or PIPS), and the minimum percent of each equipment category that had an XPS. It is a minimum value because although we tried to record every occurrence of an XPS, we did not capture all of them.

The most numerous XPSs were among computer speakers, LCD monitors, fluorescent desk lamps (whose PIPS included a magnetic ballast), powered phones (including conference and speaker phones), laptop and PDA docking stations. The highest percentage of units with XPSs were among powered phones, fluorescent desk lamps, laptop and PDA docking stations. ILPSs were prevalent among LCD monitors and laptop docking stations, while PIPSs prevailed among computer speakers, fluorescent desk lamps, powered phones and PDA docks. Equipment among which we found both ILPSs and PIPSs (though not on the same unit) were computer speakers, powered phones, PDA docks, inkjet printers, thermal printers, and scanners.

Figure 13. External Power Supplies: Number, Type and Frequency

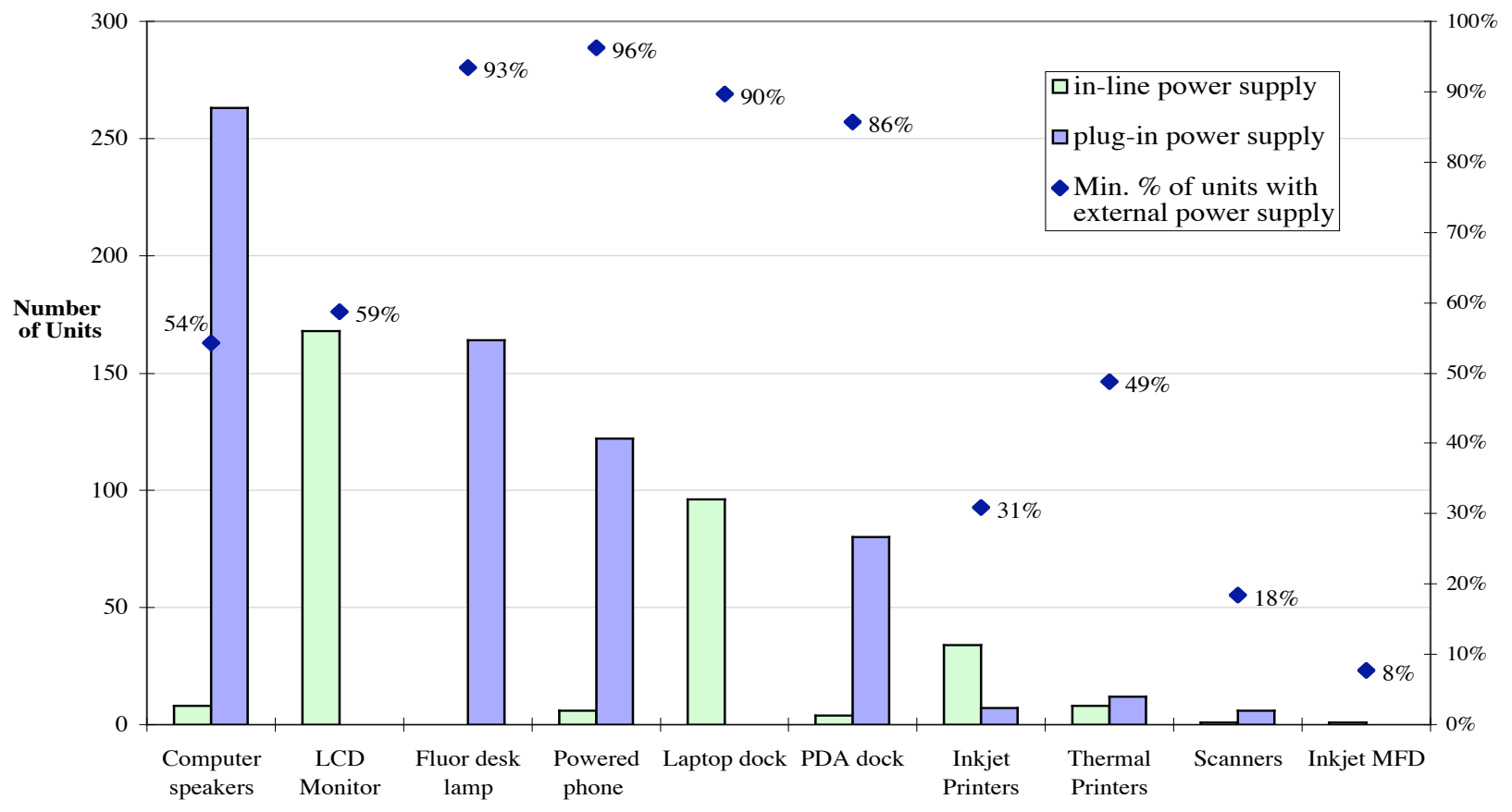




\section{Conclusions}

For all buildings combined, the average plug-load equipment density in units per 1000 gross $f t^{2}$, was about

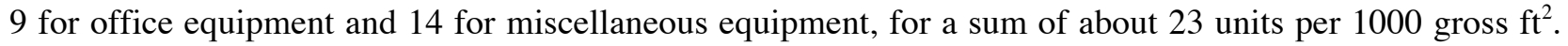
Educational buildings, where large floor areas are devoted to classrooms, had the lowest density of both office and miscellaneous equipment. However, two-thirds of computers and monitors found in educational buildings (and thus most of the energy savings potential) were concentrated in computer-based classrooms.

Among offices only (for which we were able to estimate number of employees, or occupants), the average equipment density, in units per employee, was approximately 3 units of office equipment and 6 units of miscellaneous equipment per employee, for a sum of about 9 electrical plug-load devices per employee; note that this includes equipment found in common areas such as kitchens, print centers, and utility closets. Because we have not attempted to estimate equipment density before, these data represent a baseline for reference and comparison with future data.

\section{Office Equipment}

A good overview of our results regarding office equipment power states is provided by Figure 3 (page 10), which allows a visual comparison of the percent of units found on, in low power, or off, by equipment type. Power management, indicated by the middle segment of each bar, is most successful among monitors and laser printers; and least successful among desktop computers, inkjet printers, copiers, and fax machines. Turn-off rates, indicated by the right segment of each bar, are highest ( $\geq 40 \%)$ among integrated computer systems, copiers, and scanners; and lowest $(\leq 20 \%)$ among laser printers, LCD monitors, and MFDs.

This is the first field study in which we analyzed the effect of computer power state on monitor power state. Only $6 \%$ of desktop computers in this study of commercial buildings were found in low power, and only $53 \%$ of those that were on successfully initiated power management in monitors. Computers in homes (where fewer are networked) may have higher enabling rates, but we have no data from residences. Clearly there is significant room for improvement in power management of computers, and more data are needed to identify the parameters that affect the ability of computers to power manage themselves and their monitors.

In contrast, $96-98 \%$ of monitors connected to computers that were not on were found in low power, so a very high proportion of monitors are ENERGY STAR compliant, or capable of power managing themselves.

This report presents evidence of the growing use of laptop computers. Because of their inherent portability, accounting for laptops is difficult, especially during an after-hours survey, but our conservative estimate is that laptops comprise at least $10 \%$ of the non-server computers in our sample. We also estimate that laptops outnumbered desktop computers at two sites: one medium and one large office. To the extent that relatively energy-efficient laptops are replacing desktop computers, significant electrical energy is saved. However, more work is needed to characterize laptop usage patterns and energy consumption, which can vary widely depending on how often they are used when plugged in and how often the battery is charged. Laptop power state data from this survey can be useful in developing a typical unit energy consumption for laptop computers, but needs to be supplemented by data not available from after-hours surveys.

LCD monitors, which use significantly less energy when on than CRT monitors, are also penetrating the market. They outnumbered CRT monitors at two of the twelve sites in our sample: a medium office and a university classroom building. In contrast, we found no LCD monitors at three sites: two high schools and a large office. We expect the market share of LCD monitors to continue to grow as older CRT monitors are replaced and LCD monitor technology improves and becomes more affordable due to economies of scale. 
For both types of education buildings in our sample (high schools and university classroom buildings), twothirds of computers and monitors found were in "computer labs," or classrooms with a 1:1 ratio between computer workstations and chairs. ${ }^{5}$ Some university computer labs had LCD monitors, but all the high school computer labs we visited had CRT monitors, many of which were found on after-hours. With so many workstations located in one room, and (presumably) controlled by one or very few instructor(s), we suggest efficiency efforts in high schools focus on reducing power consumed by equipment in these rooms.

Among our sample of printers, $46 \%$ were laser and $34 \%$ were inkjet. The turn-off rate was twice as high $(30 \%)$ for inkjet printers as for laser printers (15\%); inkjet printers are more likely to be turned off than laser printers because they are much less likely to be networked. Among laser printers, $77 \%$ had power management delay settings of 30 minutes or less, and only 5\% were disabled (i.e., set to "never"). This indicates a high market penetration for ENERGY STAR laser printers; however, for reasons discussed above (including error messages and after-hours network use), the actual PM rate for laser printers is lower than indicated by PM delay settings. Nevertheless, the 2003 PM rate of $60 \%$ for laser printers is higher than the 2000 PM rate of 53\% for monochrome laser printers, suggesting improvement in actual PM rates.

Eighty percent $(80 \%)$ of multi-function devices that we found used laser imaging technology; the other $20 \%$ were inkjet. For both types, the average turn-off rate was about $20 \%$, and the average PM rate was $30 \%$, significantly lower than the 56\% PM rate for MFDs observed in 2000. Power management rates among MFDs are important because MFDs appear to be replacing copiers in the workplace; the ratio of digital copier-based MFDs to copiers rose from 1:3 in our 2000 survey of office equipment to 2:1 in the 2003 survey reported here. However, while most MFDs can also fax, print, and scan, we did not observe a corresponding decrease in the relative number of fax machines, printers and scanners.

\section{Miscellaneous Equipment}

The inventory and energy consumption estimates of miscellaneous plug-load equipment presented in this report represent a first step toward characterizing the electrical demand of this large end-use category. Miscellaneous equipment outnumbered office equipment in our sample by a factor of almost two to one. While some energy-intensive devices, such as commercial refrigeration equipment, have been the target of efficiency efforts, including ENERGY STAR labeling, other less consumptive but more numerous devices, such as networking equipment and external power supplies, may offer significant energy savings potential.

According to our system of taxonomy, by far the most numerous category of miscellaneous plug-load equipment was 'power,' including power strips, surge suppressors, and external power supplies. The second most numerous category was 'lighting,' particularly undercabinet and compact fluorescent lamps, and the next most numerous category was computer 'peripherals,' $52 \%$ of which were computer speaker pairs. However, the numbers of each type of equipment do not necessarily reflect their relative energy intensity. The next step was to estimate typical unit energy consumption for the most common types of miscellaneous equipment, and begin to sort out their relative contribution to plug-load end use.

We were able to derive UEC estimates and calculate TEC for just over $70 \%$ of the types of ME found in our survey. Among miscellaneous equipment for which we have TEC estimates, equipment types with the top 50 TEC account for $85 \%$ of the total TEC - about $608 \mathrm{~K}$ of $714 \mathrm{~K} \mathrm{kWh} /$ year, respectively. The food \& beverage category accounts for $50 \%$ of the estimated $(714 \mathrm{~K} \mathrm{kWh} / \mathrm{yr})$ TEC for all miscellaneous equipment devices. This category includes refrigeration equipment (freezers, refrigerators, vending machines) that are always on, as well as ubiquitous and frequently-used devices such as coffee makers and microwave ovens.

\footnotetext{
${ }^{5}$ We do not necessarily assume a 1:1 ratio between chairs and people; occupancy rates may vary between classes.
} 


\section{Future Work}

The low rate of power management in desktop computers causes concern and deserves further investigation to ascertain barriers to computer power management as well as the most effective ways to mitigate them. One possibility would be to conduct more in-depth case studies in several types of buildings to identify specific institutional or technological impediments and evaluate the efficacy of various counter measures. Increasing power management among PCs would yield significant savings in both computers and monitors.

The increasing use of laptop computers makes it important to characterize their unit energy consumption. This would likely involve visiting offices during working hours and asking laptop users about their usage patterns, including how often the laptop is powered from a wall outlet and how often the battery is charged. It would also be useful to estimate the extent to which laptops are used in addition to or instead of desktops.

Results of this study point to the savings potential among computers and monitors in computer classrooms. We should improve our assessment of computer usage patterns in schools and develop effective strategies for realizing these savings. It would then be possible to implement prospective energy-saving measures in several computer classrooms and schools, and conduct follow-up surveys to evaluate their relative efficacy.

It would be useful to supplement these survey results with automated, network-based collection of data regarding usage patterns and power management settings of computers, printers, fax machines, and MFDs. While the former provides more detail, the latter yields significantly more data over longer periods of time.

Now that we have UECs for most common types of miscellaneous equipment, it would be possible to calculate their relative energy intensity among all buildings in our sample, or between types of buildings. Given utility bills for an individual building, we could work with building managers to estimate the portion of building energy load attributable to miscellaneous plug-load and to identify energy saving opportunities.

Additional after-hours building surveys could improve our understanding of office equipment usage and miscellaneous plug loads. Surveying a single building more than once (e.g., at weekly, monthly intervals) would help us to assess the robustness of the results from a single survey. The representativeness of our office equipment sample would be improved (compared to CBECS, for example) by visiting more large offices, and the completeness of our miscellaneous equipment inventory could be improved by ensuring that we survey their common or service areas such as network, phone and other utility closets. Furthermore, now that we have a baseline inventory of miscellaneous equipment, additional surveys and device metering would enable us to track changes in numbers and types of miscellaneous equipment, as well as their after-hours power status, and begin to characterize the typical 'plug-load profile' for various types of buildings. 


\section{References}

AD Little. 1996. Energy Savings Potential for Commercial Refrigeration Equipment.

Cadmus. 2000. Product Testing and Analysis of Water Dispensers. Memo prepared for EPA's Energy Star Program. February.

EIA. 2003. Annual Energy Outlook 2003 with Projections to 2025, Dept of Energy, Energy Information Administration, Washington DC.

EIA/CBECS. 2002. Computers and Photocopiers in Commercial Buildings. Energy Information Agency, Commercial Building Energy Consumption Survey. US Dept of Energy (DOE), Washington DC.

EPA/DOE. 2003. History of Energy Star. Thtp://208.254.22.7/index.cfm?c=about.ab_history

McCarthy, Kathryn, and R.E. Brown. 2002. (Draft) A Field Method to Quickly Detect Power State in Plug-in Devices. LBNL-54169. Lawrence Berkeley National Laboratory, Berkeley CA.

O'Sullivan, Terry, of Energy Solutions, Oakland CA. 2003. Personal Communication, November 30: Monitor power management enabling rates determined by EZ Save software.

Roberson, Judy A., G.K. Homan, A. Mahajan, B. Nordman, C.A. Webber, R.E. Brown, M. McWhinney, J.G. Koomey. 2002. Energy Use and Power Levels in New Monitors and Personal Computers. LBNL-48581. Lawrence Berkeley Lab, Berkeley CA. 36 pgs. http://enduse.lbl.gov/Info/Pubs.html

Rosen, K. and A. Meier. 1999. Energy Use of Televisions and Videocassette Recorders in the U.S. LBNL42393. March. Lawrence Berkeley National Laboratory, Berkeley CA.

Roth, Kurt, Goldstein, Kleinman. 2002. Energy Consumption by Office and Telecommunication Equipment in Commercial Buildings Volume 1: Energy Consumption Baseline. Arthur D Little Reference No. 72895-00. US DOE

US DOE. 2003. Energy Savings Estimates of Light Emitting Diodes in Niche Lighting Applications. Office of Energy Efficiency and Renewable Energy, Building Technologies Program. November.

US DOE. 1995. Technical Support Document: Energy Efficiency Standards for Consumer Products: Refrigerators, Refrigerator-Freezers \& Freezers. DOE/EE-0064.

Webber, Carrie A., R.E. Brown, A. Mahajan, J.G. Koomey. 2002. Savings Estimates for the Energy Star Voluntary Labeling Program: 2001 Status Report. LBNL-48496. Lawrence Berkeley National Laboratory, Berkeley CA. 29 pgs.

Webber, Carrie A., J.A. Roberson, R.E. Brown, C.T. Payne, B. Nordman, J.G. Koomey. 2001. Field Surveys of Office Equipment Operating Patterns. LBNL-46930. Lawrence Berkeley National Laboratory, Berkeley CA http://enduse.lbl.gov/Info/Pubs.html

Wenzel et al. 1997. Energy Data Sourcebook for the U.S. Residential Sector. LBNL-40297. Lawrence Berkeley National Lab, Berkeley CA. 


\section{Appendix A: Building Descriptions}

\section{Site A}

University classroom building, Atlanta GA

Urban, downtown campus; 4-story, circa 1970

Area surveyed includes chemistry and computer laboratory/classrooms, faculty offices, lecture hall, lobby, and storage.

\section{Site B}

Medium office, Pittsburgh PA

Headquarters of a national non-profit organization

Suburban office park, 3-story, new in 2002

Area surveyed includes computer lab/shop, conference, cubicles, custodial, kitchen, lounge, network closet, offices, print/copy centers, reception, server room, shipping \& receiving.

\section{Site C}

Large office, Atlanta GA

National headquarters of an internet company

Midtown office building, 8-story, circa 1970s

Area surveyed includes customer call center, computer classrooms, break room, conference, cubicles, .offices, and print/copy centers.

\section{Site D}

Urban high school, CA

3 -story main building, new in 2001

Area surveyed includes administrative offices, audio/visual studio, bookroom, classrooms, computer classrooms, conference, library, teachers lounge, network closet, print/copy center, utility/mechanical. Most computers are found in a few rooms, including computer classrooms and the library.

\section{Site E}

Medium office, Atlanta GA

Branch office of an international consulting firm

One floor of a 1990s suburban office tower

Area surveyed includes break room, conference, cubicles, lounge, offices, print/copy centers, server room. This office had a high percentage of laptop computers, which must be locked up or taken home at night. Only administrative staff have desktop computers, which are left on at night for backups and updates.

\section{Site F}

Urban high school, Pittsburgh PA

3-story main building, remodeled in 1990s

Area surveyed includes auditorium, cafeteria, classrooms (including art, band, language, computer classrooms, conference, library, teachers lounge, network closet, offices, storage, and A/V workroom. Most computers are found in a few classrooms and the library. 


\section{Site G}

Outpatient clinic, San Francisco CA

10-story urban medical campus building

Area surveyed includes conference, cubicles medical labs, library, lounges, exam rooms (including E/N/T, general medicine, ophthalmology, pediatric), nurses stations, offices, patient registration, phone bank, medical utility, treatment rooms, and waiting. Each exam and treatment room had a computer/monitor.

\section{Site $\mathbf{H}$}

Medium office, Atlanta GA

Information services department of a university

6-story urban campus building, circa 1970s

Area surveyed includes break room, conference, copy/print center, cubicles, custodial, lounge, network closet, offices, server room, and utility/mechanical.

\section{Site J}

Medical office building, Pittsburgh PA

Suites of physicians in private practice

5-story suburban building,

Area surveyed includes break room, conference, exam rooms (including cardiology, E/N/T, endocrinology, ophthalmology, sleep disorders, urology), kitchen, labs, offices, server room, storage, utility, and waiting.

\section{Site K}

Small office, Pittsburgh PA

5 small businesses in 3 different suburban buildings

Area surveyed includes break room, conference, copy/print center, cubicles, electronics shop, network closet, offices, server room, and storage.

\section{Site M}

Large office, Pittsburgh PA

Corporate headquarters of a major manufacturer

Urban downtown office building, 6-story, new in 2001

Area surveyed includes conference, copy/print centers, cubicles, kitchen, lounge, health center, offices. Many employees in this office use laptop computers. Company policy is to turn monitors off at night (to prevent fires); special permission is required to bring in or use small appliances (fans, heaters, lamps, etc).

\section{Site $\mathbf{N}$}

University classroom building, Atlanta GA

Urban, downtown campus; 4-story, circa 1960

The area surveyed included computer laboratories and classrooms, other classrooms, and offices of faculty, staff, and graduate students. 


\section{Appendix B: Flowchart for Auditing Desktop Computer Power State}

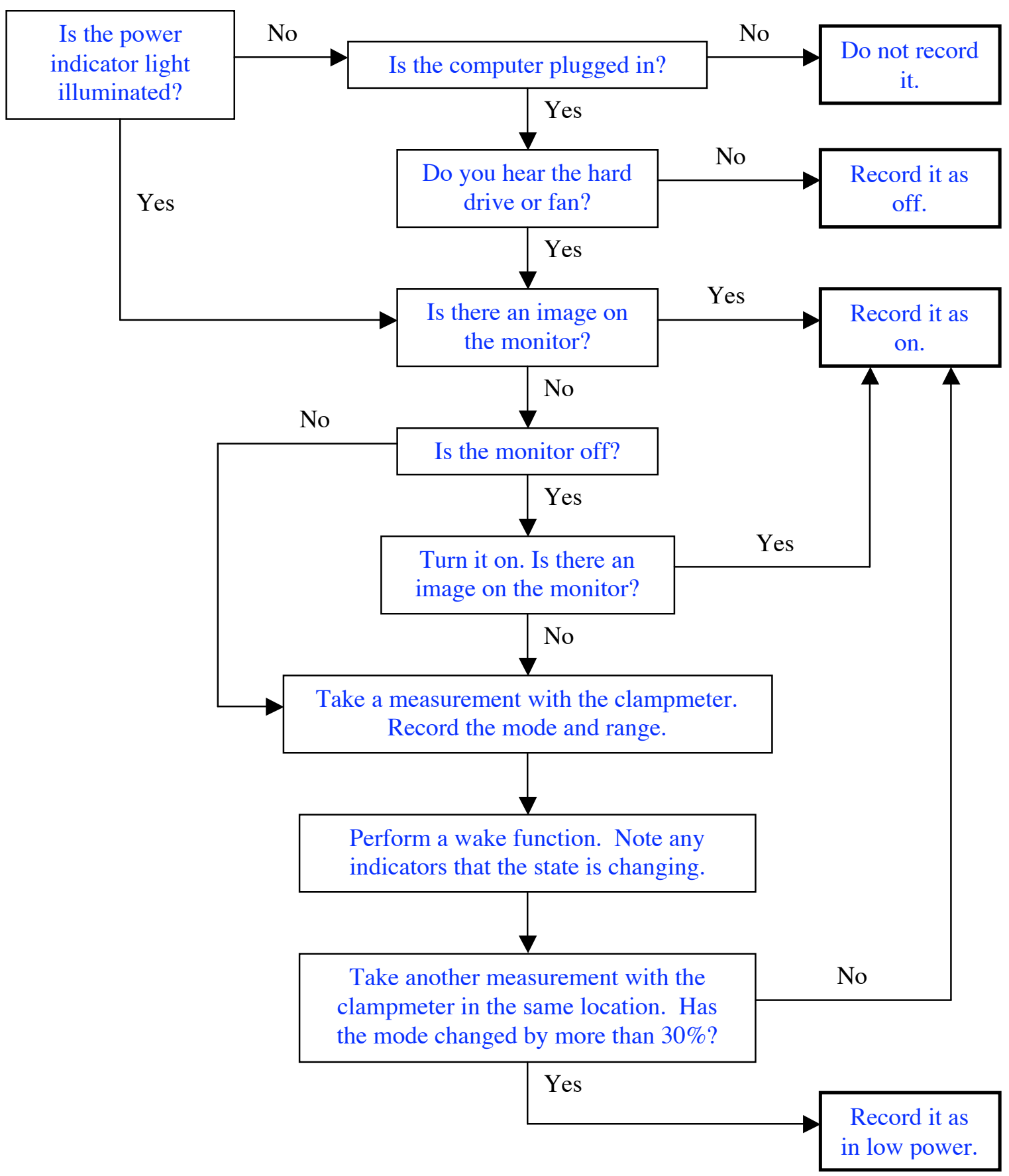




\section{Appendix C: Miscellaneous Equipment Taxonomy}

\begin{tabular}{|c|c|}
\hline Category & Equipment Type (not an exhaustive list) \\
\hline audio/visual & $\begin{array}{l}\text { television, video cassette player/recorder, overhead projector, audio amplifier, compact disk audio } \\
\text { device, digital video disk device, slide projector, video monitor, audio mixer, audio tape device, LED } \\
\text { display sign, receiver, speaker, tuner, digital video camera, video conferencing device, microfilm } \\
\text { viewer, scan converter, public address system, set-top box }\end{array}$ \\
\hline food \& beverage & $\begin{array}{l}\text { microwave oven, refrigerator (all sizes), coffee maker, toaster/toaster oven, vending machine, } \\
\text { hot/cold bottled water tap, hot pot/kettle, water cooler, freezer, hot beverage dispenser, hot food } \\
\text { cabinet, ice maker, coffee grinder, drinking fountain, fryer/griddle, steam trays, visi-cooler, meat } \\
\text { slicer, mixer, soda fountain pump, blender, refrigerated case }\end{array}$ \\
\hline hvac, portable & fan, heater, air cleaner, room air conditioner \\
\hline laboratory & $\begin{array}{l}\text { scale, spectrophotometer, tabletop centrifuge, temperature monitor, lab refrigerator, microscope, } \\
\text { autoclave, shaker/stirrer, lab freezer, hot plate/warmer, drying oven, timer }\end{array}$ \\
\hline lighting & $\begin{array}{l}\text { fluorescent undercabinet lamp (by size), desk/table/floor lamp (by lamp type and power use), } \\
\text { incandescent spotlight or studio lamp, decorative lamp, strand or cable lights, fluorescent light box, } \\
\text { incandescent or halogen track light or recessed lamp, exterior fluorescent sign }\end{array}$ \\
\hline medical & $\begin{array}{l}\text { oto-opthalmoscope charger, exam light or headlamp, x-ray light box, exam chair or table, body scale, } \\
\text { hospital bed, utensil sterilizer, blood pressure monitor, IV cart }\end{array}$ \\
\hline medical specialty & $\begin{array}{l}\text { vital signs monitor, respirator, defibrillator charger, EKG machine \& accessories, pulse oxymeter, eye } \\
\text { chart projector, lensmeter, glucometer charger, hot bead sterilizer, suction pump charger, hearing test } \\
\text { device, retinal scanner, fundus camera, hyfrecator, sonoscope }\end{array}$ \\
\hline money exchange & credit card reader, cash register, bar code scanner, change or stamp vending machine \\
\hline networking & $\begin{array}{l}\text { modem, router, hub, printer hub, switch, print controller/server, video processor, wireless access } \\
\text { point, audio/video modulator, tape drive, broadband distribution amplifier, driver }\end{array}$ \\
\hline office miscellany & $\begin{array}{l}\text { clock and/or radio, boombox or compact audio system, pencil sharpener, adding machine, shredder, } \\
\text { typewriter, stapler, postage meter or scale, hole punch, laminator, time stamper, binding machine, } \\
\text { microfiche reader }\end{array}$ \\
\hline peripheral & $\begin{array}{l}\text { computer speakers (pair), laptop docking station, personal digital assistant dock, computer projector, } \\
\text { keyboard/video/mouse switch, external drive (CD, zip, hard disk, tape backup), pen tablet, digital } \\
\text { whiteboard, }\end{array}$ \\
\hline power & $\begin{array}{l}\text { power strip, surge protector, PIPS, ILPS, uninterruptible power supply, charger (for laptop computer, } \\
\text { cell or cordless phone, power tool), power conditioner, battery backup system }\end{array}$ \\
\hline security & badge reader, book demagnetizer, shoplifting sensor, article surveillance system \\
\hline specialty & pottery wheel, mobile bookshelves, oscilloscope, shrinkwrapper, bench wheel, soldering iron \\
\hline telephony & $\begin{array}{l}\text { conference or speaker phone, answering machine, intercom, phone switch, phone jack or box, } \\
\text { dictation machine, PBX phone line converter, voice control box, switchboard phone, integrated voice } \\
\text { server }\end{array}$ \\
\hline utility/maintenance & vacuum cleaner, floor polisher, dishwasher, ultrasonic cleaner, water purifier, clothes washer or dryer \\
\hline
\end{tabular}




\section{Appendix D: Miscellaneous Equipment Numbers, by Category and Site}

Sorted in descending order

\begin{tabular}{|c|c|c|c|c|c|c|c|c|c|c|c|c|c|}
\hline $\begin{array}{r}\text { site code } \\
\text { bldg type } \\
\text { ME Category }\end{array}$ & $\begin{array}{c}\mathbf{G} \\
\text { medical }\end{array}$ & $\begin{array}{c}\text { M } \\
\text { L office }\end{array}$ & $\begin{array}{c}\text { C } \\
\text { L office }\end{array}$ & $\begin{array}{c}\mathbf{H} \\
\text { M office }\end{array}$ & $\begin{array}{c}\mathbf{F} \\
\text { school }\end{array}$ & $\underset{\text { S office }}{\mathbf{K}}$ & $\begin{array}{c}\mathbf{E} \\
\text { M office }\end{array}$ & $\begin{array}{c}\mathbf{J} \\
\text { medical }\end{array}$ & $\begin{array}{c}\text { B } \\
\text { M office }\end{array}$ & $\begin{array}{c}\text { A } \\
\text { school }\end{array}$ & $\begin{array}{c}\text { D } \\
\text { school }\end{array}$ & $\begin{array}{c}\mathbf{N} \\
\text { school }\end{array}$ & $\begin{array}{l}\text { All } \\
\text { sum }\end{array}$ \\
\hline power & 114 & 220 & 205 & 174 & 57 & 167 & 87 & 64 & 139 & 36 & 44 & 86 & 1393 \\
\hline lighting & 85 & 226 & 179 & 158 & 70 & 52 & 172 & 51 & 15 & 8 & 10 & 20 & 1046 \\
\hline plug-in power supply & 92 & 123 & 221 & 111 & 34 & 84 & 76 & 35 & 88 & 60 & 24 & 42 & 990 \\
\hline peripheral & 13 & 104 & 150 & 125 & 85 & 82 & 87 & 9 & 118 & 36 & 30 & 44 & 883 \\
\hline audio/visual & 58 & 28 & 24 & 8 & 144 & 7 & 8 & 27 & 2 & 65 & 90 & 23 & 484 \\
\hline office miscellany & 28 & 68 & 6 & 34 & 38 & 86 & 18 & 56 & 86 & 9 & 33 & 19 & 481 \\
\hline medical & 393 & 5 & & & & & & 76 & & & & & 474 \\
\hline in-line power supply & 25 & 72 & 16 & 69 & 27 & 32 & 29 & 56 & 10 & 95 & & 13 & 444 \\
\hline food/beverage & 29 & 9 & 15 & 31 & 71 & 33 & 14 & 51 & 24 & 19 & 30 & 14 & 340 \\
\hline networking & 27 & 8 & 8 & 48 & 43 & 46 & 31 & 21 & 6 & 4 & 11 & 11 & 264 \\
\hline telephony & 5 & 76 & 15 & 26 & 49 & 10 & 20 & 8 & 12 & 3 & 1 & 8 & 233 \\
\hline medical specialty & 149 & 3 & & & 2 & & & 70 & & & & & 224 \\
\hline hvac, portable & 41 & 1 & 13 & 24 & 7 & 24 & 5 & 11 & 6 & 3 & 20 & 4 & 159 \\
\hline laboratory & 44 & 1 & & & & & & 10 & & 63 & & & 118 \\
\hline utility/maintenance & 3 & & & 2 & 14 & 4 & 2 & 2 & 4 & 9 & 8 & 4 & 52 \\
\hline specialty & 1 & 2 & & & 13 & 14 & & & 3 & 1 & 9 & 1 & 44 \\
\hline money exchange & 12 & 1 & & & 3 & 3 & & 2 & 6 & 3 & 3 & & 33 \\
\hline security & & 1 & 1 & & 1 & & & & 1 & & 2 & & \\
\hline sum & 1119 & 948 & 853 & 810 & 658 & 644 & 549 & 549 & 520 & 414 & 315 & 289 & 7668 \\
\hline
\end{tabular}

Note; Plug-in and in-line power supplies are listed separately, but are actually part of the power category 